\title{
A Conceptual Design for a Mobile Application to Support Infield Inventory Activities
}

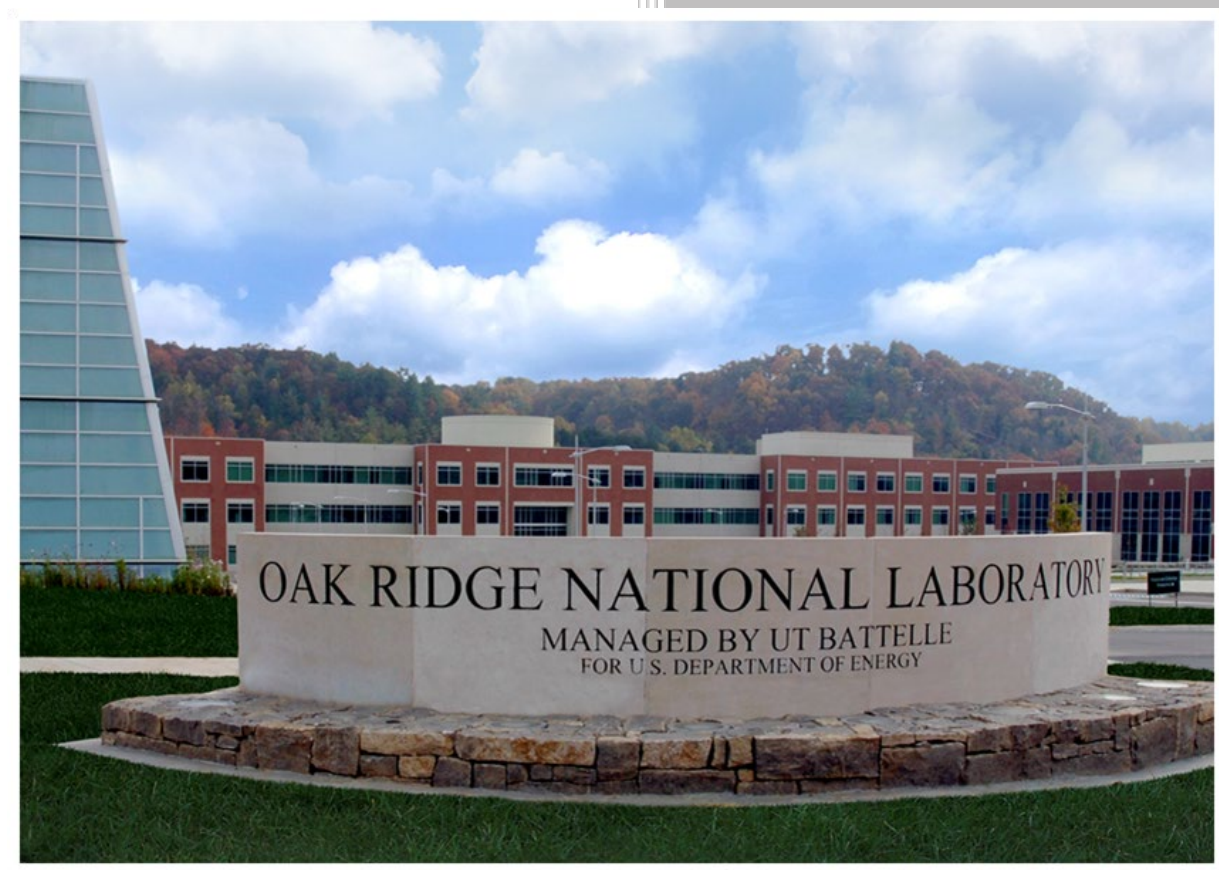

Approved for public release.

Jim Garner

Natalie McGirl

Michael Whitaker

Distribution is unlimited.

October 2020 


\section{DOCUMENT AVAILABILITY}

Reports produced after January 1, 1996, are generally available free via US Department of Energy (DOE) SciTech Connect.

Website www.osti.gov

Reports produced before January 1, 1996, may be purchased by members of the public from the following source:

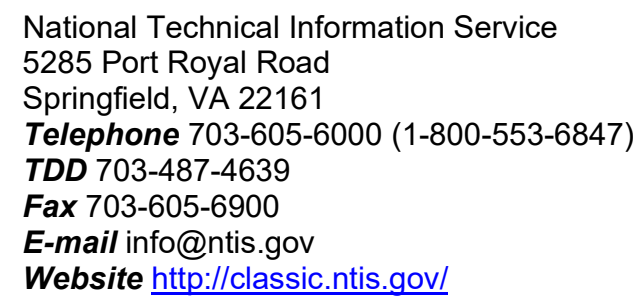

Reports are available to DOE employees, DOE contractors, Energy Technology Data Exchange representatives, and International Nuclear Information System representatives from the following source:

Office of Scientific and Technical Information

PO Box 62

Oak Ridge, TN 37831

Telephone 865-576-8401

Fax 865-576-5728

E-mail reports@osti.gov

Website http://www.osti.gov/contact.html

This report was prepared as an account of work sponsored by an agency of the United States Government. Neither the United States Government nor any agency thereof, nor any of their employees, makes any warranty, express or implied, or assumes any legal liability or responsibility for the accuracy, completeness, or usefulness of any information, apparatus, product, or process disclosed, or represents that its use would not infringe privately owned rights. Reference herein to any specific commercial product, process, or service by trade name, trademark, manufacturer, or otherwise, does not necessarily constitute or imply its endorsement, recommendation, or favoring by the United States Government or any agency thereof. The views and opinions of authors expressed herein do not necessarily state or reflect those of the United States Government or any agency thereof. 
Nuclear Nonproliferation Division

\title{
A CONCEPTUAL DESIGN FOR A MOBILE APPLICATION TO SUPPORT INFIELD INVENTORY ACTIVITIES
}

\author{
Jim Garner \\ Natalie McGirl \\ Michael Whitaker
}

Date Published: October 2020

Prepared by

OAK RIDGE NATIONAL LABORATORY

Oak Ridge, TN 37831-6283

managed by

UT-BATTELLE, LLC

for the

US DEPARTMENT OF ENERGY

under contract DE-AC05-00OR22725 



\section{CONTENTS}

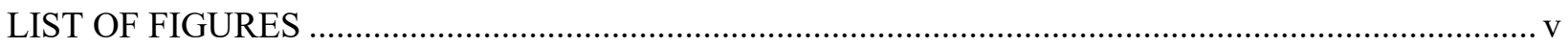

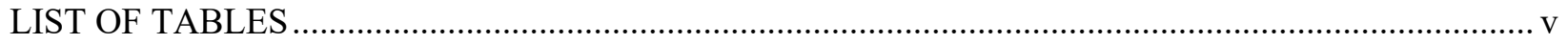

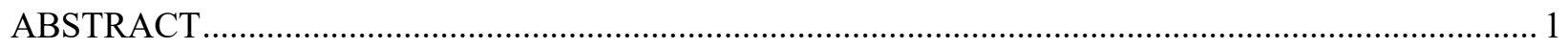

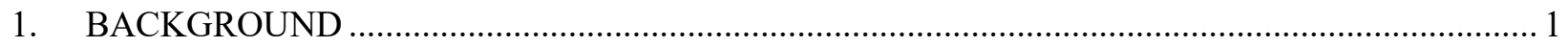

2. EXAMPLE USE CASE: IAEA ITEM COUNTING AND TAG CHECKING ACTVITIES AT

GAS CENTRIFUGE ENRICHMENT PLANTS ….................................................................... 2

3. CONCEPTUAL WORKFLOW FOR INVENTORY ASSISTANT ............................................. 4

3.1 USERS AND RESPONSIBILITIES …............................................................... 4

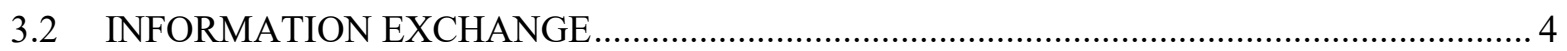

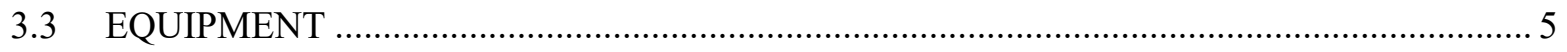

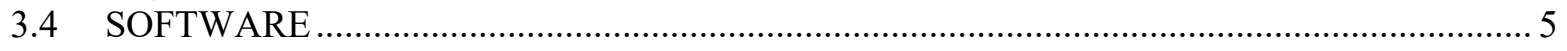

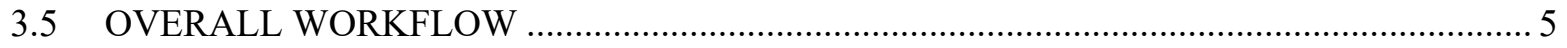

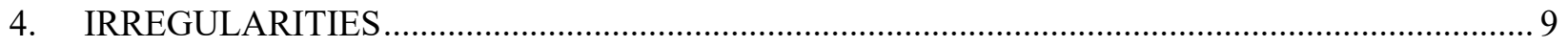

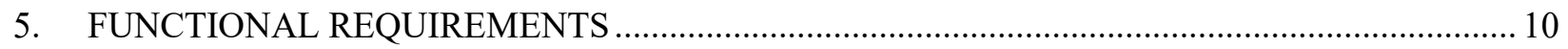

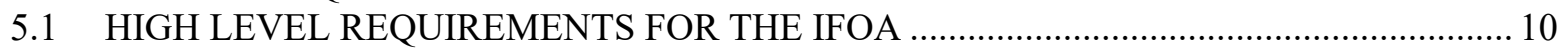

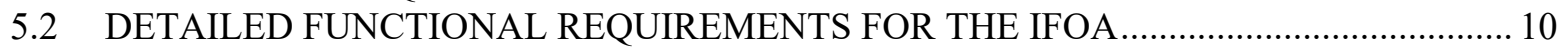

5.3 FUNCTIONAL REQUIRMENTS FOR THE MOBILE DEVICE ....................................... 11

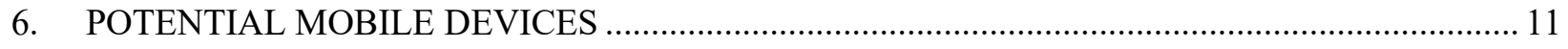

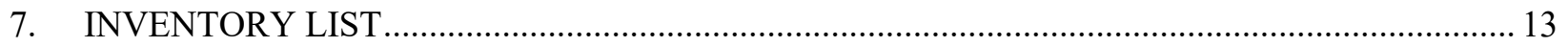

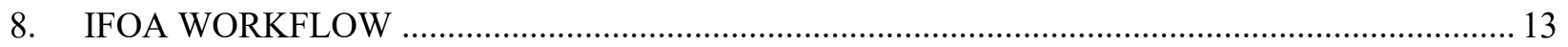

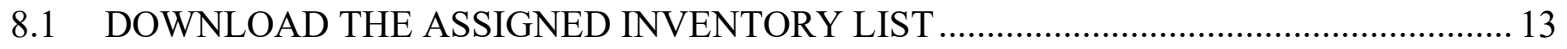

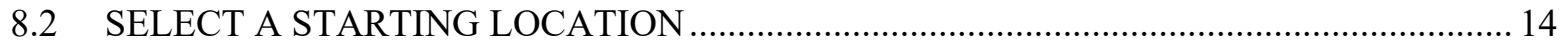

8.3 VIEW THE “TO OBSERVE” PORTION OF THE ASSIGNED INVENTORY LIST ........... 15

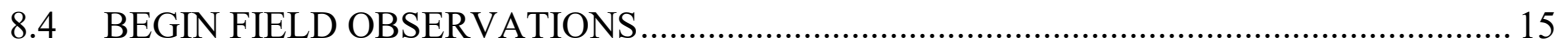

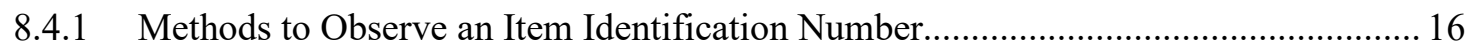

8.4.2 Item Identification Number Observation Outcomes ................................................ 17

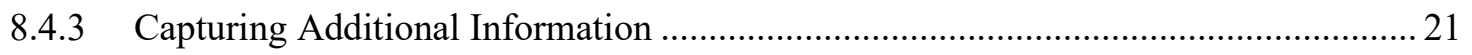

8.5 REVISE AN OBSERVATION FOR AN ITEM …..................................................... 21

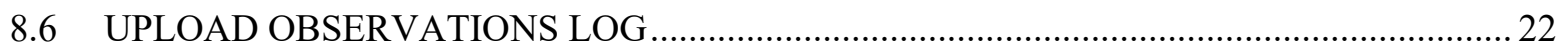

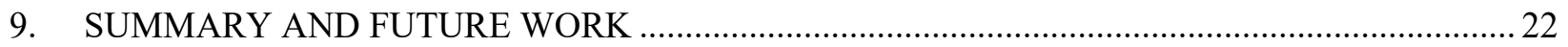

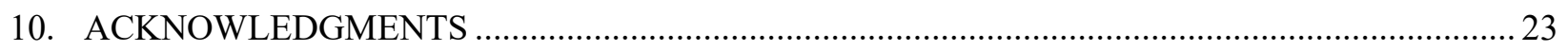

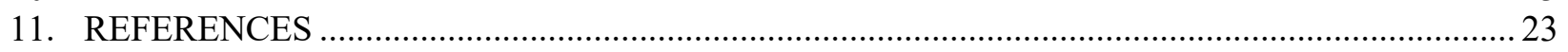

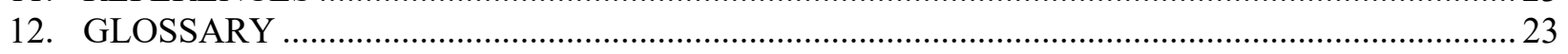

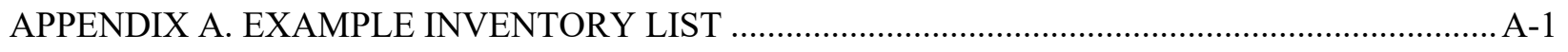

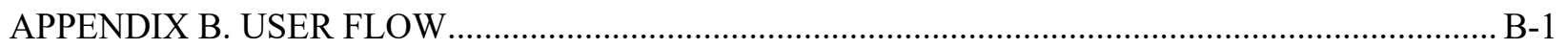





\section{LIST OF FIGURES}

Figure 1. Multiple inventory teams are typically deployed to conduct item counting and tag checking activities using a paper-based inventory listing like the one shown in the inspectors' hands.

Figure 2. Finding all of the items listed on paper-based inventory listings can be time-consuming and confusing, as illustrated by the two inspectors searching a large storage room for a cylinder of interest.

Figure 3. Information exchange key for inventory assistant workflow. ............................................ 7

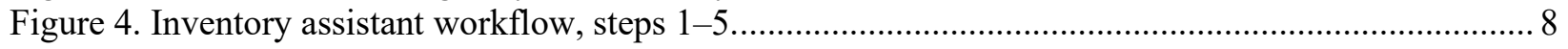

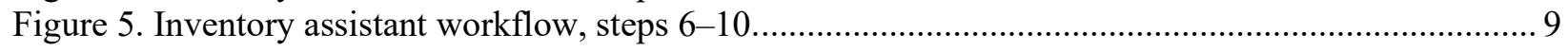

Figure 6. Cognex MX-1502 scanner with embedded Samsung Galaxy S9 smartphone. ......................... 12

Figure 7. (Left) IFOA before the assigned inventory list is downloaded from the office computer. ......... 14

Figure 8. Starting location for field observation activities................................................................ 14

Figure 9. "To Observe" inventory list ordered by location.............................................................. 15

Figure 10. The IFOA allows an inventory team to record observations................................................ 16

Figure 11. Search inventory list for a specific item identification number (e.g., cylinder serial

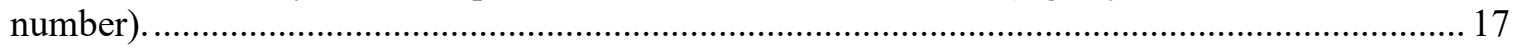

Figure 12. Item identification number is observed after scanning barcode. ...................................... 18

Figure 13. Item identification number is not on list after manual search (left)....................................... 18

Figure 14. Item identification number not on list after scanning barcode. ............................................ 19

Figure 15. Entering the location information for an item identification number added to the list..............20

Figure 16. Item previously observed page (left) ........................................................................... 20

Figure 17. Item information page containing an item's identification number, location

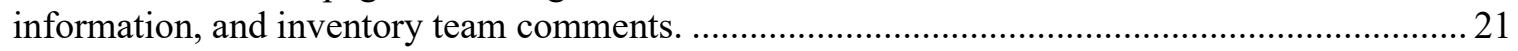

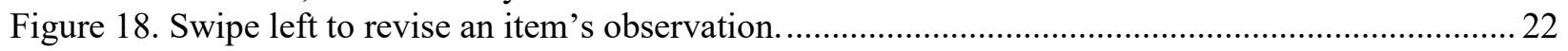

\section{LIST OF TABLES}

Table 1. Item level hierarchy and local nomenclature. 


\begin{abstract}
This paper introduces an inventory assistant being developed at Oak Ridge National Laboratory (ORNL) that we believe will empower users to perform inventory activities at nuclear facilities more accurately, reliably, and quickly. Inventory activities at nuclear facilities are often conducted using pen and paper, which can be time-consuming, tedious, and susceptible to reading or transcription errors. The proposed inventory assistant would replace the paper-based process used by International Atomic Energy Agency (IAEA) inspectors, nuclear facility operators, or verification monitors to complete an inventory of nuclear and non-nuclear items.

In general, the inventory assistant would ingest an inventory list, distribute assigned items from the inventory list to one or more mobile devices, enable inventory teams to record their observations in the field, and then enable an inventory lead to integrate and reconcile the observations to produce a final report. The assistant consists of two software components - one for the inventory teams to record observations in the field (In-Field Observations App [IFOA]) and one for the inventory lead to reconcile the inventory list with observations (Distribution, Integration, and Reconciliation Application [DIRA]). This paper introduces the overall workflow of the inventory assistant and describes the IFOA user experience in more detail.
\end{abstract}

To demonstrate the concept, the authors present a use case of IAEA inspectors conducting item counting and tag checking activities of $\mathrm{UF}_{6}$ cylinders at a gas centrifuge enrichment plant with a large number of $\mathrm{UF}_{6}$ cylinders (e.g., thousands). These activities can currently require 30-40 person-days of inspection to complete. Based on experiences during an exercised performed at the IAEA by the ORNL team in 2016, we believe an inventory assistant could allow the IAEA to complete item counting and tag checking using the global identifier or the operator's barcode in 8-10 person-days of inspection. We would expect other users (e.g., facility operators or verification monitors) to also benefit from significant time savings.

\title{
1. BACKGROUND
}

Many industries uniquely identify individual items and inventory them on a regular basis. However, commercial off-the-shelf inventory software typically requires the items to be barcoded, which is not always the case at nuclear facilities. For example, $\mathrm{UF}_{6}$ cylinders are commonly found at conversion, enrichment, and fuel fabrication facilities and can have a service life of 40 years or longer [1], [2]. Although some operators affix a vinyl label with their own identification number and a one-dimensional (1D) barcode, cylinders produced in the last few years may include a larger laser-etched global identification number and a two-dimensional (2D) barcode; the ANSI and ISO specifications only require cylinders to have a debossed (stamped) serial number on the stainless steel nameplate. To accurately and quickly perform inventory activities for a wide variety of items at nuclear facilities, an inventory assistant should be able to efficiently inventory items with only a serial number as well as those with 1D or 2D barcodes.

The use case for IAEA inspection activities at gas centrifuge enrichment plants is explored in detail in Section 2, but the proposed inventory assistant may also be valuable to other users at nuclear facilities. For example, nuclear facility operators may be interested in using this tool to inventory nuclear items or other equipment that may or may not have an affixed barcode, as well items that may have more than one identification number. For verification monitors, an inventory assistant may be used to inventory equipment or items (e.g., B-25 boxes, drums, cylinders, etc.), or to create inventory listings for previously unreported items at fuel cycle facilities. Furthermore, the proposed inventory assistant can accommodate two or more identification numbers, enhancing its flexibility in adapting to different operator practices for identifying items. 
In all scenarios, use of this inventory assistant would ease the creation and maintenance of more accurate and complete inventory listings for items with and without affixed barcodes, as well as items with multiple identification numbers.

\section{EXAMPLE USE CASE: IAEA ITEM COUNTING AND TAG CHECKING ACTVITIES AT GAS CENTRIFUGE ENRICHMENT PLANTS}

A large commercial gas centrifuge enrichment plant may have thousands of $\mathrm{UF}_{6}$ cylinders on-site. Its annual physical inventory verification could take 2-4 weeks for four to six teams of inspectors to complete item counting and tag checking activities on those cylinders. This can require up to 30-40 IAEA person-days of inspection ${ }^{1}$ with a similar burden on Euratom and proportional burden on the facility operator.

Currently IAEA item counting and tag checking activities are paper-based and do not leverage the value of existing barcodes on $\mathrm{UF}_{6}$ cylinders. The facility operator may provide the IAEA inventory lead with a paper or electronic inventory list. The inventory lead then distributes the list to their teams of inspectors. Often these teams of inspectors consist of an IAEA inspector and a Euratom inspector, as well as a facility escort. As shown in Figure 1, each team is asked to match the identification number on its assigned portion of the paper inventory list to a debossed (stamped) serial number on the stainless steel nameplate or to the operator's identification numbers printed on a vinyl label [3]. This process is timeintensive, requiring the inventory teams to laboriously find and read the identification number as marked on the cylinder, find the corresponding identification number on the paper list, and then manually mark it off. $^{2}$ As a result, this process is potentially prone to reading or character or number transposition errors. When a $\mathrm{UF}_{6}$ cylinder cannot be found in its listed location, the inspectors may need to extensively search the facility, which may contain thousands of cylinders (Figure 2).

\footnotetext{
${ }^{1}$ According to the IAEA, a person-day of inspection is a day during which a single inspector has access to a facility at any time for a total of no more than 8 hours [4].

${ }^{2}$ The following link shows typical activities that occur during an IAEA inspection at a nuclear fuel cycle facility: https://www.youtube.com/watch?v=Pf1MtMxnEEc
} 


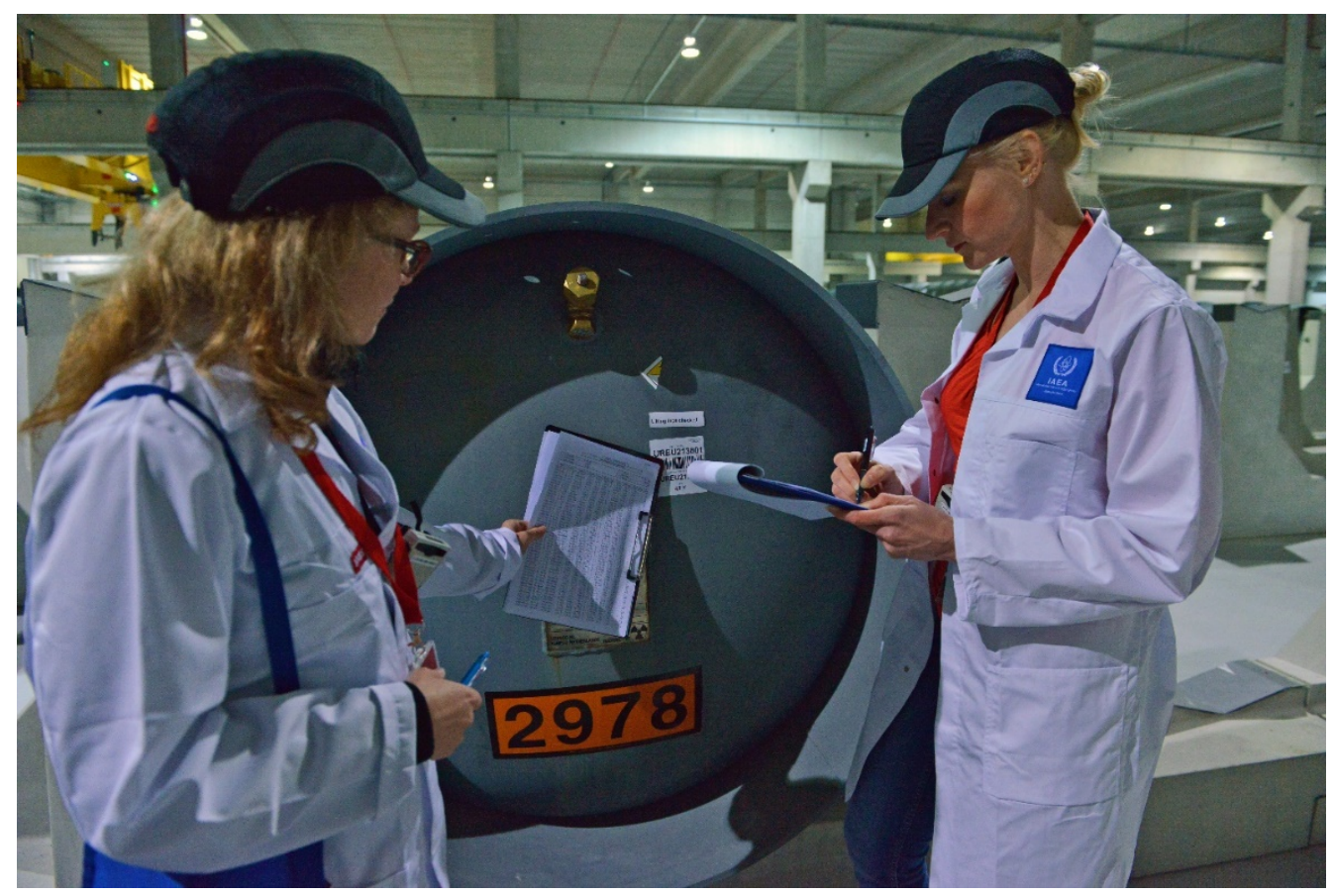

Figure 1. Multiple inventory teams are typically deployed to conduct item counting and tag checking activities using a paper-based inventory listing like the one shown in the inspectors' hands. ${ }^{3}$

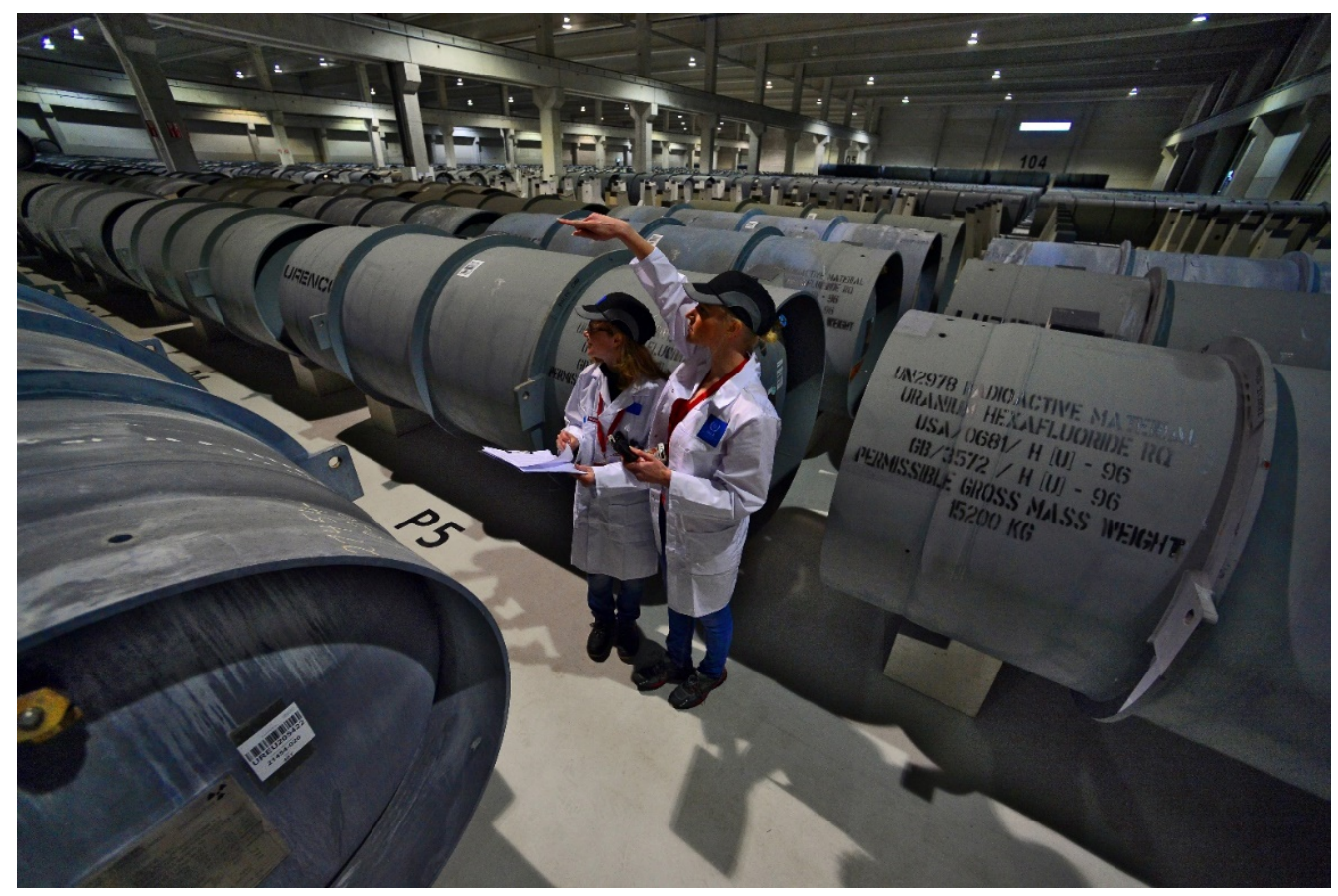

Figure 2. Finding all of the items listed on paper-based inventory listings can be time-consuming and confusing, as illustrated by the two inspectors searching a large storage room for a cylinder of interest. ${ }^{4}$

${ }^{3}$ Source: https://www.flickr.com/photos/iaea imagebank/22166534096/in/album-72157659464420989/

${ }^{4}$ Source: https://www.flickr.com/photos/iaea_imagebank/22192664675/in/album-72157659464420989/ 
Once the inventory teams have attempted to locate the items on their portion of the inventory list, the inventory lead then must collect and merge the hand-written forms and manually identify and tabulate any differences. Irregularities are common, including cylinders on the inventory list that were not observed in the field, cylinders observed in the field that are not on the inventory list, or separate teams that report observing the same cylinder [3]. The inventory lead must then reconcile these irregularities with the operator before producing a final report.

\section{CONCEPTUAL WORKFLOW FOR INVENTORY ASSISTANT}

The ORNL team envisions that the inventory assistant would have a component for activities to be conducted in an office at the facility as well as a component that would be used in the field at the facility (cylinder yard, feed and withdrawal area, etc.). In the on-site office, the inventory lead could use software on a desktop or laptop computer to ingest the inventory list and distribute the assigned items to the inventory teams. In the field, each inventory team would make observations about the items on their portion of the inventory list or about other items that they observe. Once the inventory teams had attempted to complete their portion of the inventory list, the inventory lead would use software on a desktop or laptop computer back in the office to try to reconcile any irregularities between the inventory list and observations and produce a final report.

\subsection{USERS AND RESPONSIBILITIES}

1. Facility Operator: The point of contact at a given facility who is responsible for providing the inventory list to the inventory lead.

2. Inventory Lead (lead): The lead is responsible for determining the number of inventory teams and assigning portions of the operator-provided inventory list to each team. The number of teams per facility is typically dependent upon the number of items on the list, size of the facility, and number of persons available for the activity. Once the field observations are complete, the lead will download and combine the observations logs produced by the inventory teams, identify any irregularities from the inventory list, and reconcile with the facility operator. Once the irregularities are addressed, the lead generates a final summary report.

3. Inventory Team (team): Each inventory team consisting of one or more persons reports to the inventory lead. Each team is responsible for downloading their assigned inventory list onto their mobile device, entering the item storage location, recording their observations, and synchronizing observations logs to the office computer.

\subsection{INFORMATION EXCHANGE}

The inventory assistant will exchange the following types of information between its components.

1. Inventory List: Operator-provided list of items to be observed (e.g., XML, CSV, JSON, or another file type).

2. Assigned Inventory List: The inventory list with portions assigned by the inventory lead to specific inventory teams. Although the full inventory list will be transmitted to all teams, each team is only prompted to record their observations on their assigned portion.

3. Observations Log: The log of observations recorded by each inventory team. The observations log would be time-stamped and attributable to specific teams. The observations log contains information 
on the status of the assigned inventory list with comments, as well new entries for observed items not on the provided inventory list and observed items with duplicate identification numbers.

4. Summary Report: The inventory lead generates a summary report that contains the status of recorded observations for all listed items and all additional items observed that were not on the operatorprovided inventory list.

\subsection{EQUIPMENT}

1. Operator Computer: An operator-controlled laptop or desktop computer used to provide the inventory list to the inventory lead.

2. Office Computer: A Windows 10 laptop or desktop computer that contains the datastore and runs the DIRA. It interfaces with the operator's computer and the mobile device(s).

3. Mobile Device: An Android smartphone, an iOS smartphone, or a Windows 10 tablet that interfaces with the office computer and runs the IFOA. One device is distributed to each inventory team. Sample screens shown throughout later portions of this document were designed for a Samsung Galaxy S9 embedded in a Cognex MX-1502 barcode scanner. The examples in this document are shown for the 5.8 inch screen of the Samsung S9, but the concepts described are equally applicable for landscape screens, which might make sense with tablets like the Panasonic CF-33. The Cognex MX-1502 is described more fully in Section 6.

4. Mobile Device Dock: A docking station that connects each mobile device to the office computer.

\subsection{SOFTWARE}

1. Distribution, Integration, and Reconciliation Application (DIRA): This application is installed on the office computer. The inventory lead uses it to
a. exchange information with the datastore,
b. assign portions of the inventory list to specific inventory teams,
c. compile field observations and reconcile irregularities, and
d. generate the summary report.

2. In-Field Observations App (IFOA): This application is installed on each mobile device. The inventory teams use it to exchange information with the datastore and to record the observations log.

\subsection{OVERALL WORKFLOW}

The overall workflow of the inventory assistant including proposed users, equipment, and software is discussed in the steps described below. Figure 3 provides a key for the symbols used to describe the types information exchanged.

1. The facility operator uses the operator computer to 
- Step 1. Upload the inventory list to the datastore ${ }^{5,6}$ (Figure 4)

2. The inventory lead uses the DIRA on the office computer to

- Step 2. Download the inventory list from the datastore (Figure 4)

- Step 3. Assign portions of the inventory list to different inventory teams (Figure 4)

- $\quad$ Step 4. Upload the assigned inventory lists to the datastore (Figure 4)

3. Each inventory team uses the IFOA on the mobile device to

- Step 5. Download the assigned inventory list from the datastore (Figure 4)

- Step 6. Record observations. Each observation is time-stamped to create an observations log (Figure 5)

- Step 7. Upload their observations log to the datastore (Figure 5)

4. Inventory lead uses the DIRA on the office computer to

- Step 8 . Download the observations $\operatorname{logs}$ submitted by the individual inventory teams from the datastore (Figure 5)

- Step 9. Integrate the observations logs with the inventory list and reconcile any irregularities with the inventory teams or operator (Figure 5)

- Step 10. Generate a summary report (Figure 5)

\footnotetext{
${ }^{5}$ One implementation approach may be to use a web server (e.g., Internet Information Services, Apache, or Tomcat) to provide an accessible location to store data files from the various components.

${ }^{6}$ Another option to investigate involves creating a capability for the inventory lead to scan and convert a paper copy of the inventory list.
} 


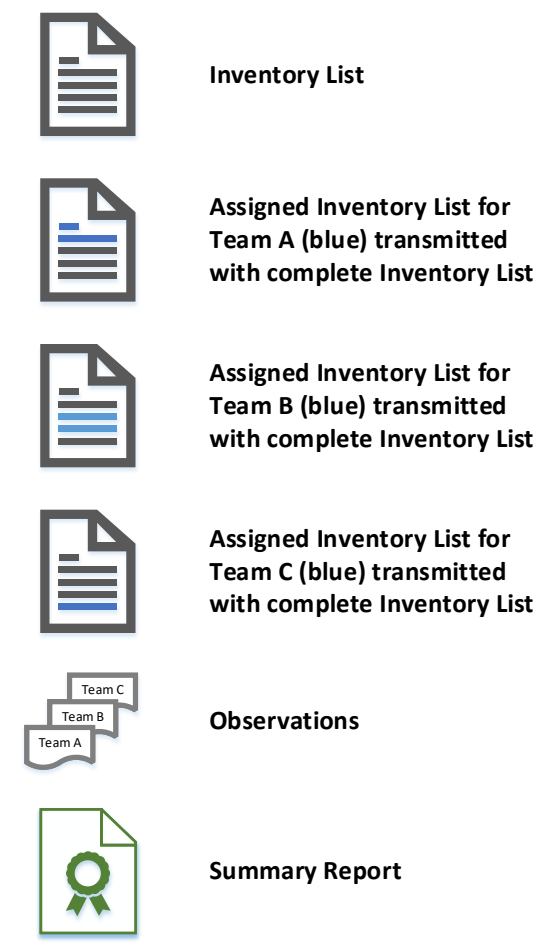

Figure 3. Information exchange key for inventory assistant workflow. 


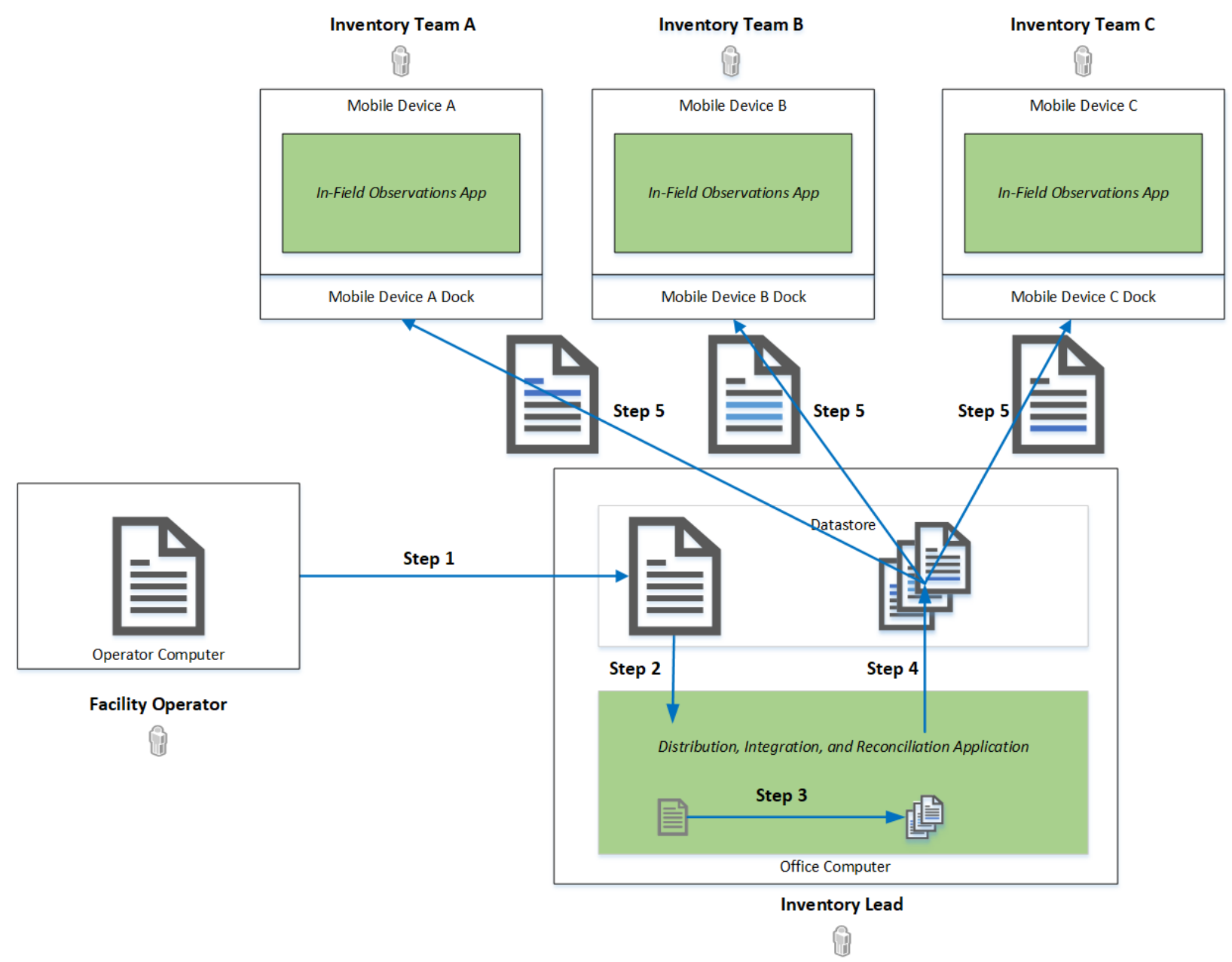

Figure 4. Inventory assistant workflow, steps 1-5. The inventory lead downloads the inventory list on the office computer and then distributes the assigned inventory lists to the mobile devices. 


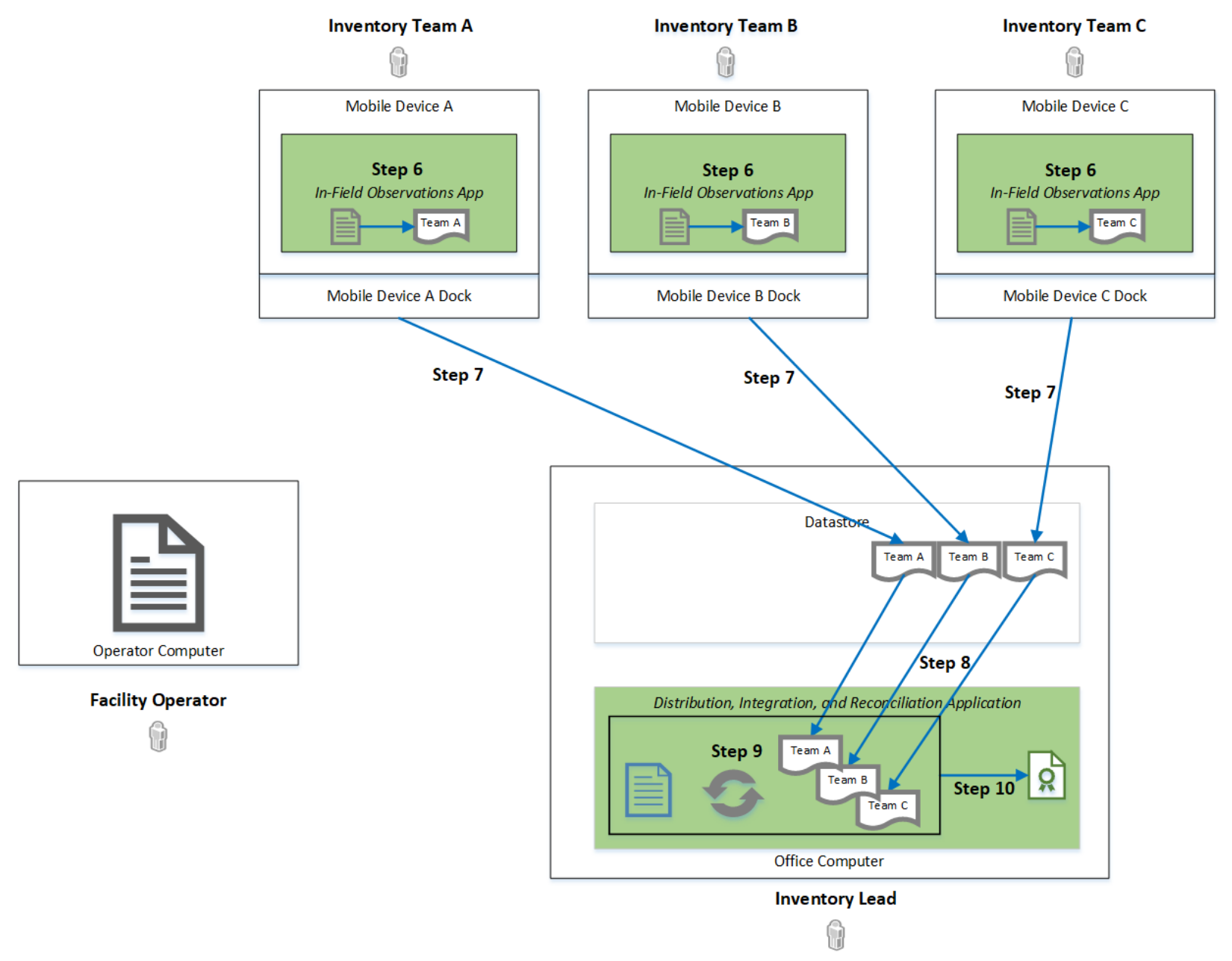

Figure 5. Inventory assistant workflow, steps 6-10. Inventory teams using the mobile devices record timestamped observations. The inventory lead uses the DIRA on the office computer to integrate observations with the inventory list, reconcile any irregularities, and generate a summary report.

\section{IRREGULARITIES}

Ideally, the inventory list matches the items observed in the field, but we anticipate that some irregularities could arise. For example, perhaps an observed item is not included on the inventory list, an item on the inventory list is not observed in the field, or the inventory team incorrectly marks an item as observed. Generally, the IFOA is designed to record observations as naturally as possible for inventory teams in the field, and reconciliation of irregularities is reserved for the inventory lead in the office on the DIRA.

We expect each team's "Assigned Inventory List" to be prominently displayed in the IFOA on their device, but the complete "Inventory List" would also be available. As such, some irregularities could be observed in the field, whereas others will only appear after all observations logs are integrated on the DIRA. For example, a team could scan the barcode for an item that is included on another team's "Assigned Inventory List." The observation would be recorded as "Observed - Wrong Team" on the IFOA, which would be flagged for the inventory lead to acknowledge on the DIRA on the office computer. Similarly, if two teams each observed the same item, those observations would be recorded on 
each team's mobile device. Neither team would know the other team observed the same item until the reconciliation process. To accommodate this and other scenarios in which observations made by separate teams must be reconciled, the inventory assistant is designed to capture observations efficiently on the mobile device and reconcile irregularities on the office computer.

A more in-depth description of the potential irregularities, how they would present themselves and how they could be reconciled using the inventory assistant is beyond the scope of this document but described in forth coming documents that describe the DIRA in more detail.

\section{FUNCTIONAL REQUIREMENTS}

\subsection{HIGH LEVEL REQUIREMENTS FOR THE IFOA}

To efficiently complete the inventory activities in the field, the inventory team needs to be able to

1. quickly record their observations for their assigned inventory list with the least amount of error,

2. record items observed in the field but that are not on their assigned inventory list, and

3. understand their assigned inventory list when working with other inventory teams.

Each team must know where to begin and end their assigned item observation activities. Often, field observation activities take more than 1 day, so the team also needs the ability to pause at the end of the day and resume where they left off the next day.

\subsection{DETAILED FUNCTIONAL REQUIREMENTS FOR THE IFOA}

A. The app will provide the inventory team with the following capabilities:

1. Download their assigned inventory list from the office computer. The items assigned to other inventory teams will also be downloaded.

2. Upload observations to the office computer.

B. The app should suggest a starting location (place, section, etc.) for inventory activities and allow the team to select an alternative starting location.

1. Further, it should display the assigned inventory list sorted by location, presenting the next expected "To Observe" item based on the last item observed.

C. The app should enable the inventory team to record their field observations in three ways:

1. Scanning a barcode on the item (e.g., the global identifier)

2. Selecting an item identification number from the "To Observe" inventory list displayed on the screen

3. Typing the observed identification number to search the full inventory list and selecting the item from the search results.

D. The app should enable the inventory team to complete the following actions: 
1. View items on their assigned inventory list as well as the full inventory list. The IFOA will indicate if items are assigned to other teams (e.g., items assigned to other teams may be grayed out and shown below the assigned inventory list).

2. Revise an observation in the case where the inventory team recorded an observation in error (i.e., move an item from the "Observed" inventory list to the "To Observe" inventory list).

3. Filter/sort the inventory list. The full inventory list is searchable by all inventory teams; however, observations from other teams are not accessible.

4. Add comments about items including when items are observed in an unexpected location.

E. The app should allow the inventory team to indicate irregular observations, such as the following examples:

1. Observed item is on the assigned inventory list of a different inventory team.

2. Observed item is not on the inventory list and is added to the list by the inventory team (i.e., the item is not on the assigned inventory list of any team).

3. An item's identification number has already been observed by the inventory team.

\subsection{FUNCTIONAL REQUIRMENTS FOR THE MOBILE DEVICE}

The mobile device should

- $\quad$ be lightweight and portable;

- have a battery life of at least 8 hours on a single charge;

- have a large, readable touchscreen;

- quickly respond to standard touchscreen gestures with accuracy and speed;

- function in indoor and outdoor environments, including low light areas; and

- function in a variety of weather conditions including cold, hot, dusty/dirty, and wet environments.

\section{POTENTIAL MOBILE DEVICES}

The IFOA is installed on a mobile device and is used by the inventory teams to record their observations in the field. The ORNL team initially developed the prototype IFOA software to run on a Samsung Galaxy S9 smartphone embedded in a Cognex MX-1502 optical scanner (Figure 6). The Cognex scanner interfaces with the IFOA to allow quick, easy, and reliable scanning of many types of barcodes. These commercial, off-the-shelf units were selected because of their suitability to read the 2D barcode proposed by the World Nuclear Transport Institute standard [1] and the ability to easily adapt between iOS or Android smartphones. 


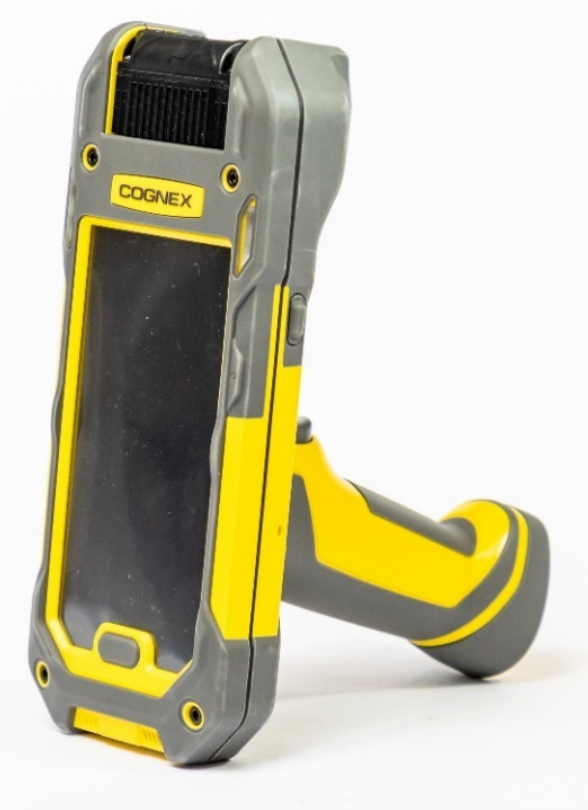

Figure 6. Cognex MX-1502 scanner with embedded Samsung Galaxy S9 smartphone.

Nuclear facilities can have stringent requirements about allowing devices in secure areas. In the past, offensive hardware could be physically removed from electronics before they were permitted to enter secure areas. As devices have become smaller, they have become much more tightly integrated, which makes it increasingly difficult to find devices that can have offensive components removed. At this point, the ORNL team could not identify any Android or iOS devices that could be modified to have the offensive components physically removed. Instead, mobile device management is the modern approach to enforce restrictions on the use of wireless, camera, microphone, GPS, and other capabilities built into many smartphones. Most of the contemporary flagship products from Apple (iPhone 6, 6 Plus, 6s, 6s Plus, 7, 7 Plus, 8, 8 Plus, X, Xs, XS Max, Xr, and SE) and Samsung (Galaxy S8, S8+, S9, S9+, S10, $\mathrm{S} 10+, \mathrm{S} 10 \mathrm{E})$ have been evaluated for conformance to the international standard common criteria. In the United States, these products are all included on the National Security Agency's Commercial Solutions for Classified Program list of end-user devices. ${ }^{7}$

If necessary, the Samsung Galaxy S9 could be locked down using the Samsung Knox protocol to ensure compliance with a site's security requirements for mobile devices. If a mobile device management solution like the Samsung Knox platform is insufficient or not worth the effort to be permitted at a site, alternative hardware-disabled solutions would need to be pursued. The ORNL team evaluated several potential alternative hardware solutions including products from Dell, HP, and Panasonic. A product like the Panasonic CF-33 rugged Windows $10-$ based tablet ${ }^{8}$ could be an appropriate alternative to the Samsung Galaxy S9 embedded in the Cognex MX-1502 optical scanner because it can be modified to physically remove any offensive capabilities.

To accommodate flexibility and the desire to migrate to a mobile device that could be hardware-disabled, the prototype IFOA was developed using Xamarin.Forms. Xamarin.Forms is a cross-platform framework

\footnotetext{
${ }^{7}$ https://www.nsa.gov/resources/everyone/csfc/components-list/

${ }^{8}$ https://na.panasonic.com/ns/271752_TOUGHBOOK_33_spec sheet_january_2020.pdf
} 
that provides the ability to compile the same source code to Universal Windows Platform, iOS, and Android executables.

\section{INVENTORY LIST}

Appendix A is an example inventory list that an operator may provide to an inventory lead. In this example, the inventory list includes a primary identification number (e.g., serial number), secondary identification number (e.g., global identification number), and location information for the item. The proposed inventory assistant is flexible enough handle two identification systems and could be extended to handle more.

The organizational structure of item locations may vary between facilities, but items such as cylinders are typically arranged in a logical hierarchy with different levels and varying level nomenclature. Table 1 provides several examples for each of the levels, and Appendix A contains an example item listing illustrating how the location of items may be specified by its building assignment (level 0), row number (level 1), position on a row (level 2), and its stacked vertical location (level 3). Other items in the facility may be more generally organized by building (level 0 ) and area (level 1). In either case, the variability in the organizational structure and the large number of items in a facility will affect the length of time required to perform an inventory.

Table 1. Item level hierarchy and local nomenclature.

\begin{tabular}{ccc}
\hline Hierarchy & Level Nomenclature & Other examples \\
\hline Level 0 & Place & Building, Raft \\
Level 1 & Section & Row, Column, Feed, Product, Tails, Feed Purification \\
Level 2 & Position & Position \\
Level 3 & Vertical Location & Vertical Location \\
\hline
\end{tabular}

\section{IFOA WORKFLOW}

The sections below describes the IFOA process that each inventory team will use to download the assigned inventory list from the office computer to their mobile device, record observations in the field, and upload the observations log from their mobile device to the office computer. Note, these screenshots are from prototype software, and the exact word choice may not directly reflect the text in this document. The full user flow for the IFOA is shown in Appendix B.

\subsection{DOWNLOAD THE ASSIGNED INVENTORY LIST}

Once the inventory lead has completed the assignments for the inventory teams, each inventory team will connect their mobile device to the mobile device dock and download their assigned inventory list from the office computer to their mobile device. Figure 7 shows example screens before (left) and during (right) the download process for the assigned inventory list. 


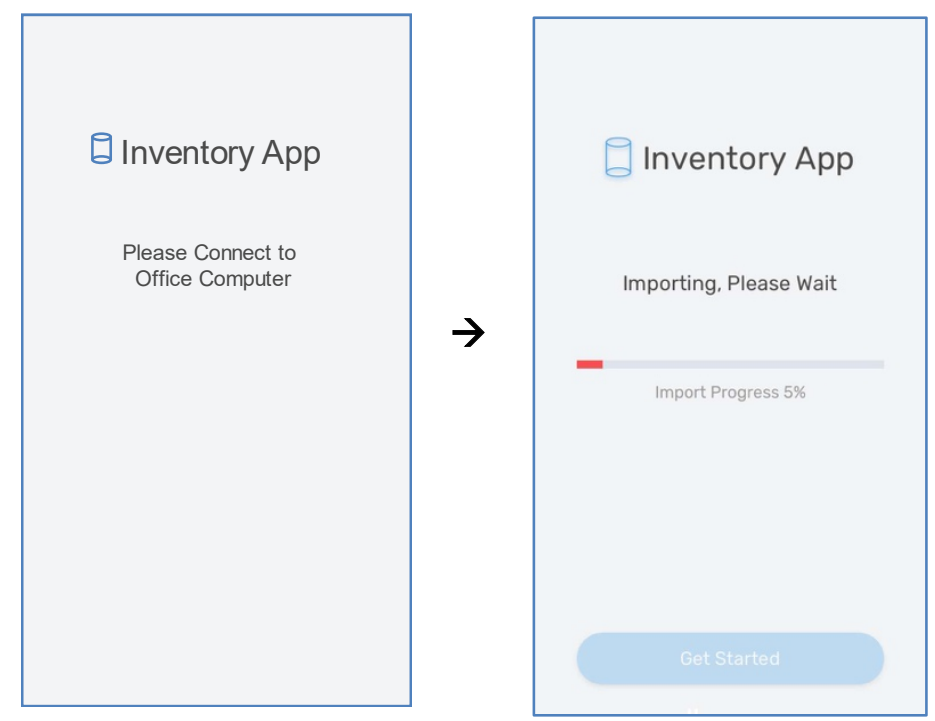

Figure 7. (Left) IFOA before the assigned inventory list is downloaded from the office computer. (Right) IFOA during the download process.

\subsection{SELECT A STARTING LOCATION}

An example of the starting location screen is shown in Figure 8. The inventory team could begin their field observation activities in the suggested location or select a new location. The displayed options will be based on their assigned inventory list.

The inventory team could use the stepper buttons or the drop-down menus to select a different place (e.g., a building or raft) and section (e.g., a row, column) to begin their field observation activities.

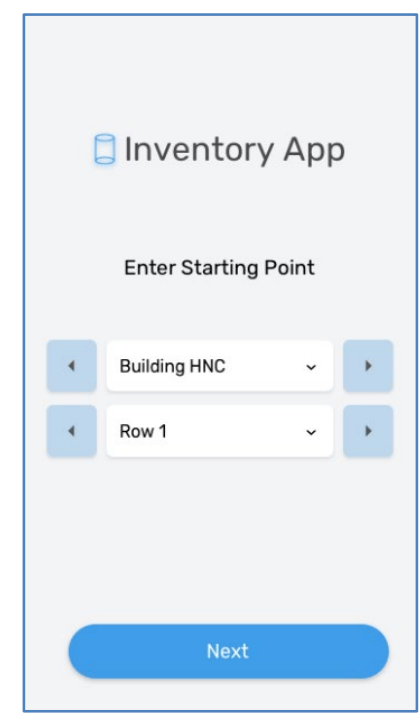

Figure 8. Starting location for field observation activities. 


\subsection{VIEW THE "TO OBSERVE" PORTION OF THE ASSIGNED INVENTORY LIST}

Once the starting location is selected, the IFOA will display the "To Observe" inventory list from their assigned inventory list (Figure 9). Each item's identification number (e.g., serial number or global identification number for a $\mathrm{UF}_{6}$ cylinder) is displayed. The items are ordered by location. Items that should have a barcode (e.g., cylinders with a global identification number) are displayed with a twodimensional Data Matrix barcode icon to the right of the text. The barcode icon should indicate to the inventory team that the item should have a barcode to scan and an easy-to-read representation of the identification number.

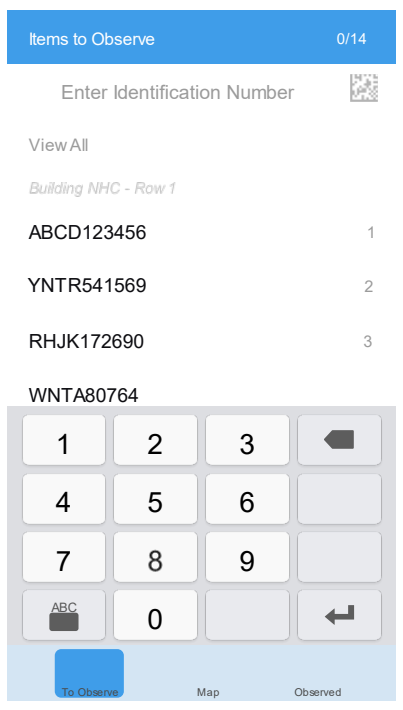

Figure 9. "To Observe" inventory list ordered by location. Items with a 2D barcode show a Data Matrix icon to the right of the identification number (e.g., item YNTR541569).

The items shown on the "To Observe" inventory list are displayed in the order they are expected to appear based on the location provided by the operator. If the next observed item is not the next item displayed on the screen, the inventory team can search for the item by typing an identification number in the search bar. Once the item is observed, the displayed "To Observe" inventory list reorders based on the location of the item that was last observed.

\subsection{BEGIN FIELD OBSERVATIONS}

As shown in Figure 10, there are several ways to record observations. The inventory team can scan an item's barcode, swipe right on an item's identification number, or manually search for the item's identification number and then swipe right. Several possible outcomes are also possible for each observed item. 


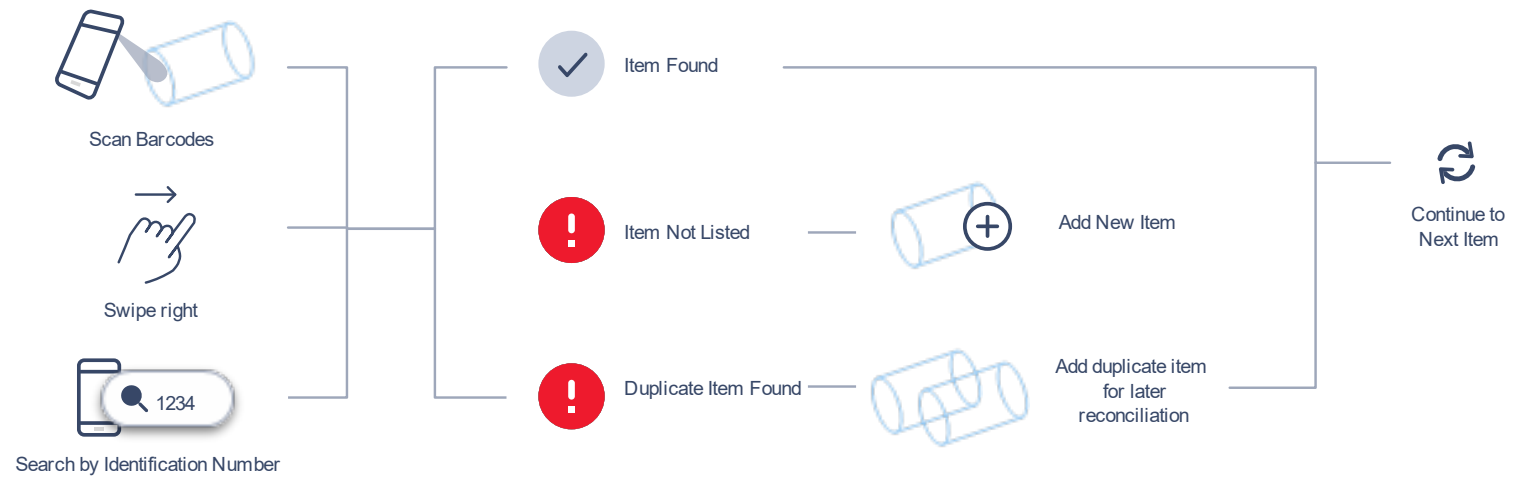

Figure 10. The IFOA allows an inventory team to record observations.

\subsubsection{Methods to Observe an Item Identification Number}

\subsubsection{Scan Barcode on an Item}

The inventory team can scan barcodes they find on items. The IFOA will attempt to match the barcode to an identification number from the inventory list. Section 8.4.2 describes the potential observations that may be recorded.

\subsubsection{Swipe Right to Select Item Identification Number from "To Observe" Inventory List}

When no barcode is available, the inventory team can browse the "To Observe" inventory list (Figure 9). By default, the items will be displayed by location. The item at the top of the list should be the next one an inventory team might encounter based on the location of the last observed item or starting location. Ordering the list in this way is intended to limit the need to manually search the "To Observe" inventory list by identification number and should therefore increase the efficiency of the observation process. Once the appropriate item identification number is observed, the inventory team can swipe right to record an observation for an item, moving it from the "To Observe" inventory list to the "Observed" inventory list. If the item was on that team's assigned inventory list, then a normal observation (i.e., "Observed") is recorded. If the item was on the assigned inventory list of another team, the observation is recorded as "Observed - Wrong Team" and will be flagged for the inventory lead to review on the DIRA during the reconciliation process.

\subsubsection{Manually Search for Item Identification Number}

When no barcode is available and when the item identification number is not displayed near the top of the "To Observe" inventory list, the inventory team can search the full inventory list by identification number. The inventory team can enter any portion of an identification number into the application search bar, as shown in Figure 11. By default, a numeric keypad with a larger hit area is displayed to provide a better user experience than the full alphanumeric keyboard. 


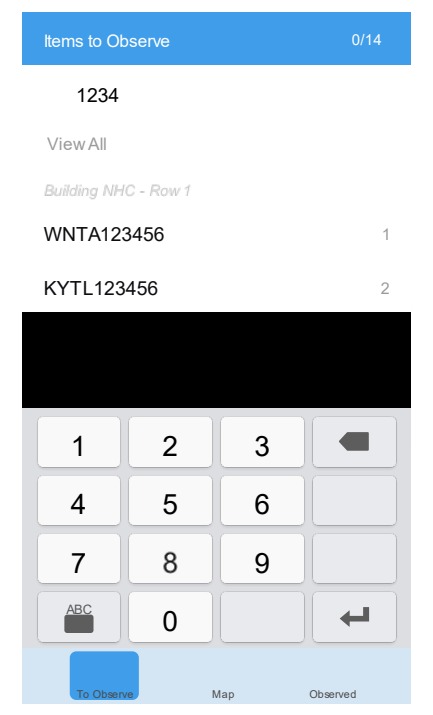

Figure 11. Search inventory list for a specific item identification number (e.g., cylinder serial number).

As the inventory team enters characters in the search bar, the IFOA will filter to only show item identification numbers that match the search query. Item identification numbers assigned to the inventory team will appear at the top of the search results with a white background. Items assigned to other inventory teams will appear at the bottom in gray. An inventory team can swipe right to observe the item identification number and move the item from the "To Observe" inventory list to the "Observed" inventory list.

If a full identification number is entered and no items match on the full inventory list, then the inventory team can follow the workflow to add the item to the inventory list as described in Section 8.4.2.2 below.

\subsubsection{Item Identification Number Observation Outcomes}

The IFOA can record normal (i.e., "Observed") and irregular observations. Examples of potential irregular observations include when an item is not on the inventory list but is observed in the field, when an item identification number has already been observed by the same inventory team, and when an item is observed in an unexpected location. Note, after all the field observations logs are uploaded to the office computer, the DIRA helps the inventory lead reconcile observations that may involve more than one inventory team. This includes situations when an item identification number is observed by multiple inventory teams or when an item identification number is observed by the wrong inventory team.

\subsubsection{Item identification number is observed}

If an inventory team observes an identification number for the first time using any of the three methods described in Section 8.4.1, a notification is displayed (e.g., "Confirmed Scan" as shown in Figure 12), the item will be moved from the "To Observe" inventory list to the "Observed" inventory list, and the number of remaining "Items to Observe" is updated. If the item was originally assigned to this inventory team, a normal (i.e., "Observed") observation is recorded. However, if the item was part of another inventory team's assigned inventory list, then the observation is recorded as "Observed - Wrong Team" and will be flagged for the inventory lead to review on the DIRA. 


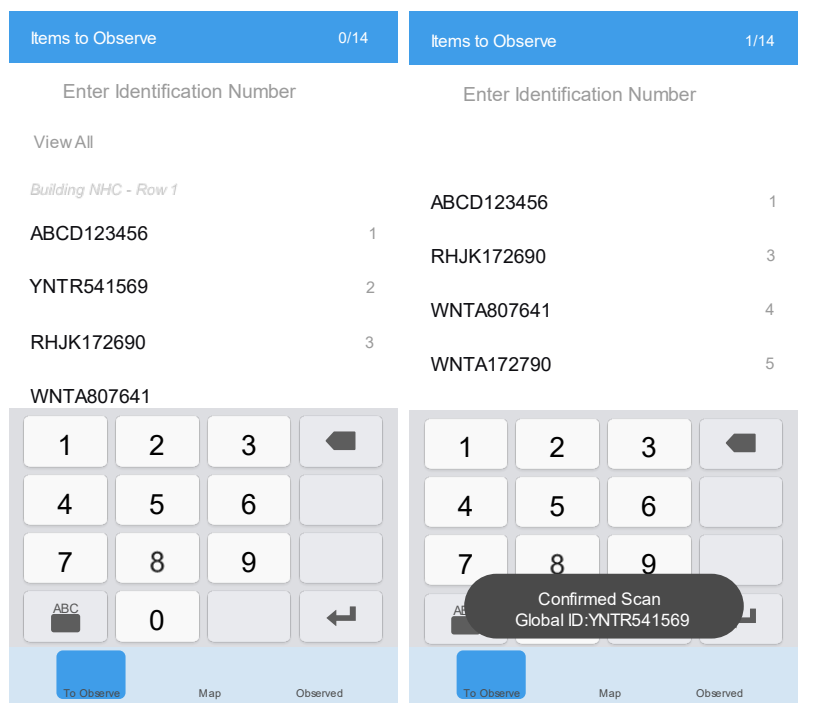

Figure 12. Item identification number is observed after scanning barcode.

\subsubsection{Item identification number is added to list}

An inventory team could observe an item identification number that is not on their assigned "To Observe" inventory list or the full inventory list. As soon as an inventory team has typed in enough characters for the item identification number to exclude the remaining items, the IFOA displays the screen shown in Figure 13 (left). From this screen, the inventory team can select the "Add Item" button. This takes the inventory team to a new screen where they must enter the item's location (Figure 13, right). The location will be automatically populated based on the location of the most recently observed item, but the inventory team can change as necessary.

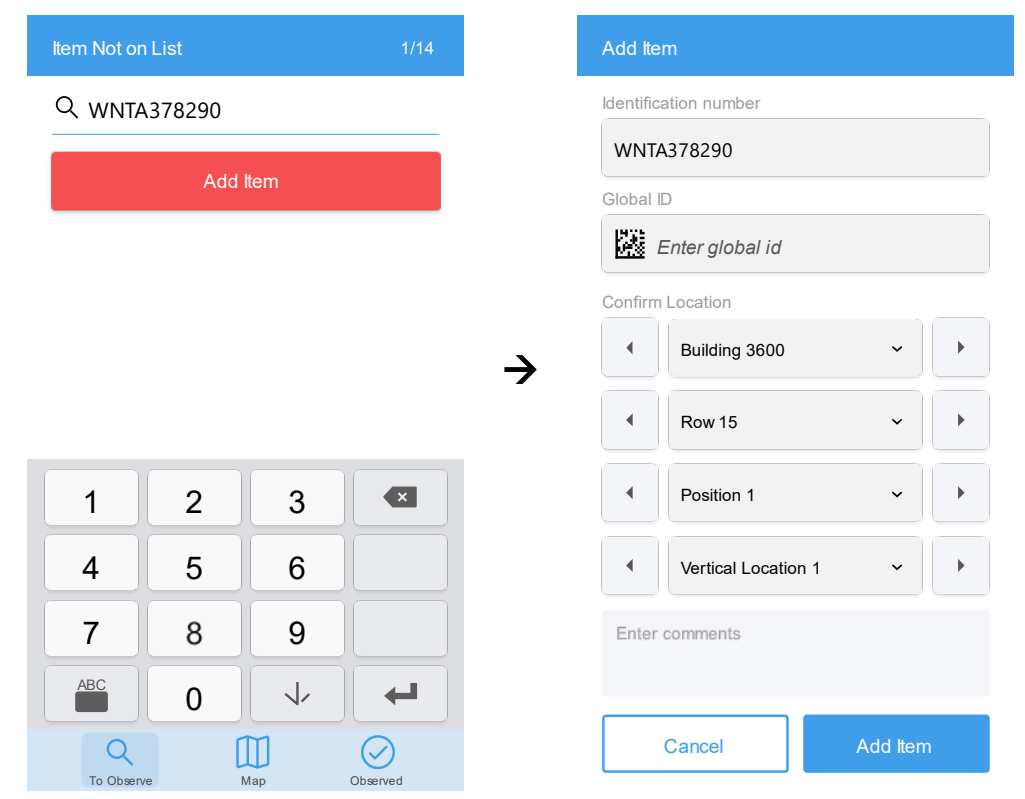

Figure 13. Item identification number is not on list after manual search (left). Observations about unlisted items can be added (right). 
Similarly, if the inventory team scans an item's identification barcode and the associated identification number is not on the inventory list, the IFOA will display an "Add Item" screen (Figure 14). This screen allows the inventory team to record an observation about an unlisted item. The location fields are automatically populated based on the location of the most recently observed item, but the inventory team can change as necessary.

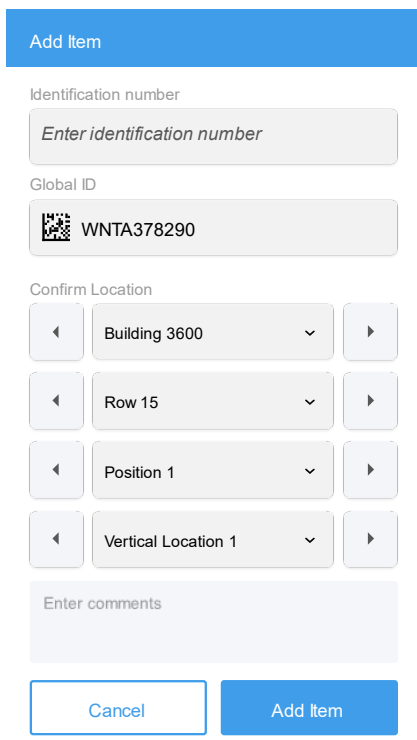

Figure 14. Item identification number not on list after scanning barcode. Enter the item's location and click "Add Item" to record an observation about this previously unlisted item.

To adjust the location of an item being added to the list, the inventory team can use the stepper on either side of the location fields to incrementally navigate through previously enumerated entries. Clicking on a location field button will trigger a pop-up to select from the previously enumerated locations or allow an inventory team to enter a new place. Figure 15 shows how an inventory team could select from a previously enumerated location, whereas Figure 47 in Appendix B shows how an inventory team could "Enter New Place." Because this observation was for an unlisted item, the observation would be flagged on the DIRA on the office computer for the inventory lead to review. 

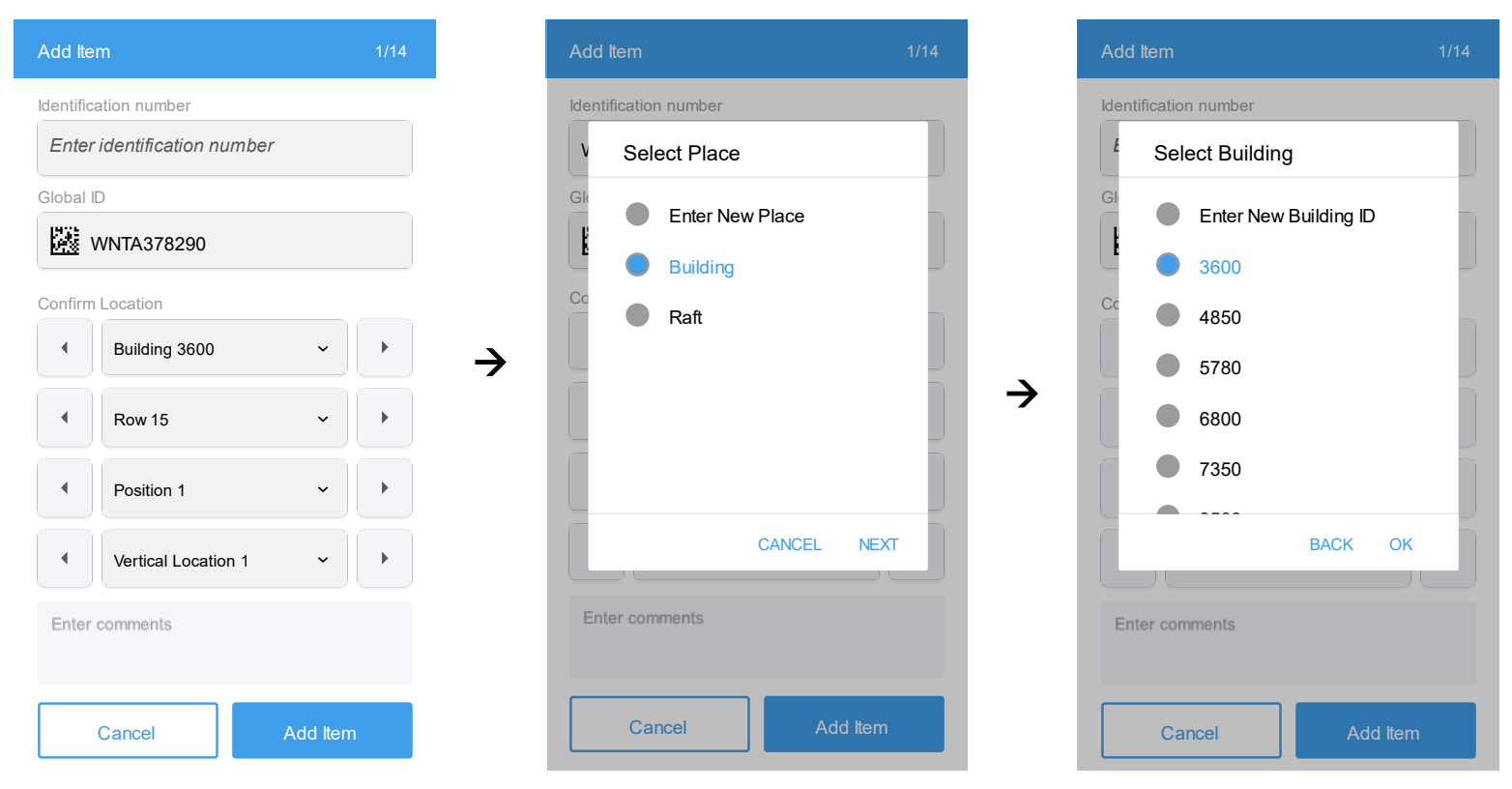

Figure 15. Entering the location information for an item identification number added to the list.

\subsubsection{Duplicate item identification number found}

If, after the entire identification number is entered into the search bar, an item with the same identification number has previously been observed by the inventory team, the "Item Previously Observed" screen will appear (Figure 16, left). This screen shows the location and the time that the item was previously observed. If the cylinder to be observed is a different item with the same identification number, the inventory team can select the "Duplicate" button (Figure 16, left) and confirm the item's location (Figure 16 , right). The item is then moved to the "Observed" inventory list and is flagged in the observations log for resolution by the inventory lead in the DIRA.

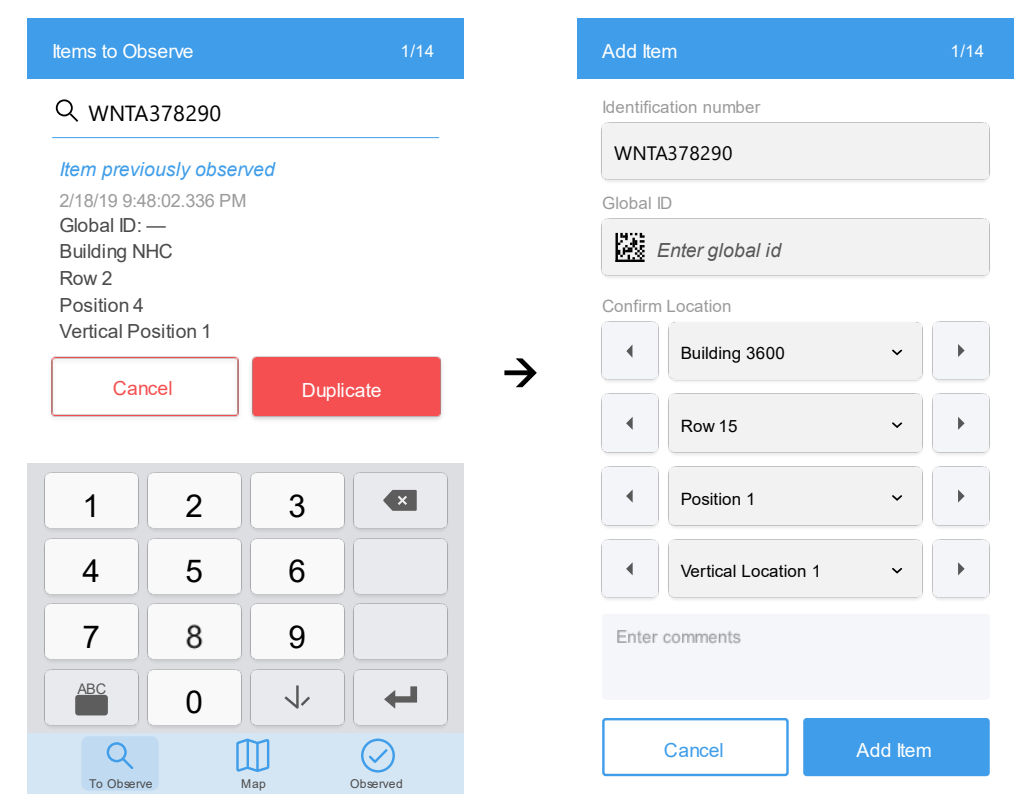

Figure 16. Item previously observed page (left). Confirm location of duplicate item (right). 


\subsubsection{Capturing Additional Information}

\subsubsection{Item observed in unexpected location}

The IFOA is designed to show the next expected item at the top of the screen. If the next item encountered is not listed at to the top of the "To Observe" inventory list, an inventory team can enter the identification number in the search bar. If the item is found on the "To Observe" inventory list, but was not listed at the top, the inventory list may have incorrect location information for that item. The inventory team may add a comment to update the location information for an item.

To acquire more information about an item and to show existing comments, the inventory team can longtap on the item's identification number to open an item information screen (Figure 17). This screen includes information about an item's primary and secondary identification numbers as well as location information and any existing comments. The inventory team can then tap in the comments box to bring up an alphanumeric keyboard to enter free-form comments. The method could be used to include comments about an item's as found location or any other notes.

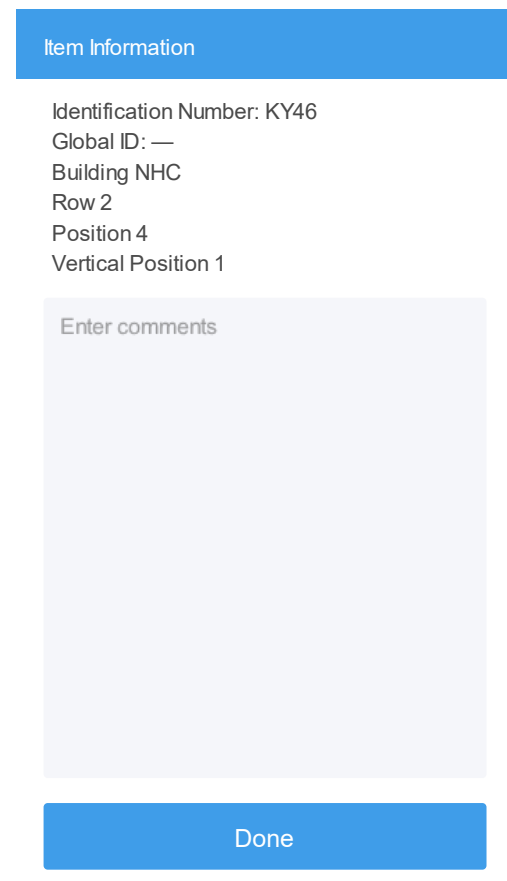

Figure 17. Item information page containing an item's identification number, location information, and inventory team comments.

\subsection{REVISE AN OBSERVATION FOR AN ITEM}

Once an item is observed, the identification number is removed from the "To Observe" inventory list and displayed on the "Observed" inventory list. The "Observed" inventory list is ordered by when the item was observed with the most recent observation displayed at the top. The inventory team can revise an observation for an item if it was accidentally or incorrectly observed by swiping left on the item identification number of interest, as shown in Figure 18. The item identification number is then removed from the "Observed" inventory list, and a notification is displayed. The item is displayed on the "To Observe" inventory list when the inventory team navigates to that list. Although the identification number would now be shown on the "To Observe" inventory list and not shown in the "Observed" inventory list, 
the inventory team actions would be recorded and flagged for the inventory lead's review using the DIRA.

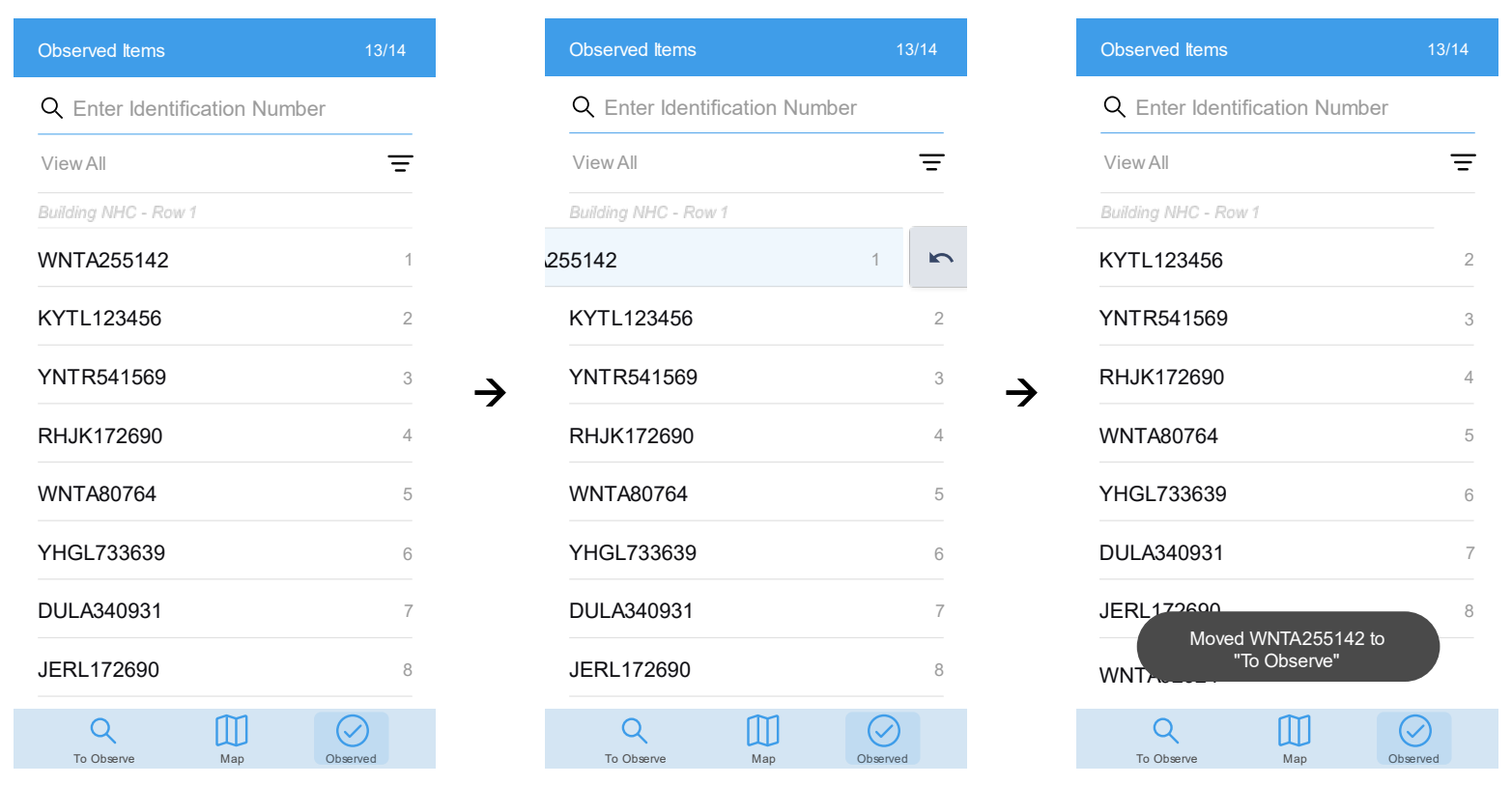

Figure 18. Swipe left to revise an item's observation. List of "Observed" items after the inventory team accidentally observed item WNTA255142 (left). List of "Observed" items during the team's swipe left action to revise item WNTA225142's observation (middle). Item WNTA221542 is removed from the "Observed" inventory list (right). WNTA221542 would be displayed on the "To Observe" inventory list.

\subsection{UPLOAD OBSERVATIONS LOG}

At any time, an inventory team can upload the observations log from their mobile device back to the office computer. Two cases must be considered:

A. The inventory team wants to periodically upload their observations log even if the team has not completed their assigned inventory list (e.g., at the end of the day).

B. The inventory team needs to upload their observations log once they have completed the assigned inventory list.

To upload an observations log, the inventory team must connect their mobile device to the mobile device dock, which is connected (via network or USB) to the office computer. The inventory lead then uses the DIRA to download the observations log. Observations logs downloaded to the office computer are not automatically cleared from the mobile devices because an inventory inspection may occur over multiple days. The DIRA will have the functionality to clear the IFOA via input from the inventory lead.

\section{SUMMARY AND FUTURE WORK}

The inventory assistant is being developed to increase the efficiency and effectiveness of field observation activities conducted at nuclear facilities. The IFOA installed on a mobile device will allow an inventory team to search and record observations for items through a variety of methods, including scanning a barcode, swiping right on an identification number that is immediately visible on the assigned inventory list, and searching the assigned inventory list and full inventory list for an identification number. The 
IFOA also records observations about irregularities such as observing multiple items with the same identification number, observing items that were not on the inventory list, or adding comments about the unexpected location for specific items.

Future work for the inventory assistant includes developing the user interface and functionality for the DIRA and potentially field testing both prototype systems with potential end users such as IAEA inspectors.

Owing to its versatility compared to current paper-based approaches, the proposed IFOA could be used by IAEA inspectors, nuclear facility operators, or verification monitors to complete an inventory of nuclear and non-nuclear items in a more timely and accurate manner.

\section{ACKNOWLEDGMENTS}

The authors would like to thank Mike Ellis and Megan Gaylor at Cadre5 for their user experience design work presented throughout this report. Additionally, the authors would like to thank Ed Wonder of Ayr Hill Group LLC (subcontractor to Brookhaven National Laboratory) for his technical reviews and helpful comments.

\section{REFERENCES}

1. World Nuclear Transport Institute Standard, $\mathrm{UF}_{6}$ Cylinder Identification, Version 1, 2017.

2. White-Horton, J., et al., The Life Cycle of 30B and 48Y Cylinders, Report no. ORNL/TM-2011/522, Oak Ridge National Laboratory, Oak Ridge, TN, April 2012.

3. Cooley, J., et al., Opportunities for the IAEA to use a UF 6 Global Identifier for Safeguards, Report no. ORNL/TM-2017/283, Oak Ridge National Laboratory, Oak Ridge, TN, June 2017.

4. International Atomic Energy Agency. IAEA Safeguards Glossary, 2001 Edition, International Nuclear Verification Series No. 3, Vienna, 2002.

\section{GLOSSARY}

Assigned inventory list: Portion of the inventory list assigned to a specific inventory team.

Distribution, Integration, and Reconciliation Application (DIRA): Windows application installed on office computer used to distribute the assigned inventory list to each inventory team, integrate inventory team observations with the inventory list, reconcile irregularities and produce a final inventory report.

Global identification number: "Standardized format for the ID used across industry, not duplicated" [1].

Global identifier: "A metal plate permanently attached to $\left[a \mathrm{UF}_{6}\right]$ cylinder containing a 10-character cylinder ID displayed in both textual and two-dimensional barcode form" [1].

Inventory list: List of items provided by the facility.

In-Field Observations App (IFOA): App installed on each mobile device to record observations.

Machine-readable: “A capability of being read using an instrument (e.g., barcode scanner); an individual does not have to visually read the ID and transcribe it to another media" [1]. 
Observation: Time-stamped record from an inventory team.

Person-day of inspection: "A day during which a single inspector has access to a facility at any time for a total of not more than 8 hours" [4].

Place: "Usually means a smaller area or point on a site." [4] Name that describes the level 0 prefix in the location hierarchy. For this document, the level 0 prefix refers to a building or raft in the location hierarchy, but the place name may be configurable depending upon the site.

Position: Name that describes the level 2 prefix in the location hierarchy and represents what location the inspector is in within a section. The position name may be configurable depending upon the site.

Revising an observation: Undoing an observation for a specific item.

Section: Name that describes the level 1 prefix in the location hierarchy. In this document, the level 1 prefix refers to a row, column, feed, product, tails, or feed purification in the location hierarchy, but the section name may be configurable depending upon the site.

Site: As defined in Article 18.b of INFCIRC/540, that area delimited by the State in the relevant design information for a facility where nuclear material is customarily used [4].

Vertical location: Name that describes the level 3 prefix in the location hierarchy and describes the location of how the items are stacked. This vertical location name may be configurable depending upon the site. 

APPENDIX A. EXAMPLE INVENTORY LIST 



\section{APPENDIX A. EXAMPLE INVENTORY LIST}

Table A.1. Example UF 6 cylinder inventory list and location hierarchy in a storage area.

\begin{tabular}{|c|c|c|c|c|c|c|c|c|c|c|}
\hline $\begin{array}{c}\text { Cylinder } \\
\text { ID }\end{array}$ & $\begin{array}{c}\text { Serial } \\
\text { Number }\end{array}$ & $\begin{array}{c}\text { Global } \\
\text { Identifier }\end{array}$ & $\begin{array}{l}\text { Level0 } \\
\text { Prefix }\end{array}$ & Level0 & $\begin{array}{l}\text { Level1 } \\
\text { Prefix }\end{array}$ & Level1 & $\begin{array}{c}\text { Level2 } \\
\text { Prefix }\end{array}$ & Level2 & $\begin{array}{l}\text { Level3 } \\
\text { Prefix }\end{array}$ & Level3 \\
\hline 1 & 162970 & UREU162970 & Building & 4850 & Row & 1 & Position & 1 & $\begin{array}{l}\text { Vertical } \\
\text { Location }\end{array}$ & bottom \\
\hline 2 & LU2201 & LUZU002201 & Building & 4850 & Row & 1 & Position & 2 & $\begin{array}{l}\text { Vertical } \\
\text { Location }\end{array}$ & bottom \\
\hline 3 & UREU103367 & & Building & 4850 & Row & 1 & Position & 3 & $\begin{array}{l}\text { Vertical } \\
\text { Location }\end{array}$ & bottom \\
\hline 4 & LUZU001212 & LUZU001212 & Building & 4850 & Row & 1 & Position & 4 & $\begin{array}{l}\text { Vertical } \\
\text { Location }\end{array}$ & bottom \\
\hline 5 & LU0720 & LUZU000720 & Building & 4850 & Row & 1 & Position & 11 & $\begin{array}{l}\text { Vertical } \\
\text { Location }\end{array}$ & bottom \\
\hline 6 & LUZU002153 & LUZU002153 & Building & 4850 & Row & 2 & Position & 1 & $\begin{array}{l}\text { Vertical } \\
\text { Location }\end{array}$ & bottom \\
\hline 7 & BNFU000089 & BNFU000089 & Building & 4850 & Row & 2 & Position & 2 & $\begin{array}{l}\text { Vertical } \\
\text { Location }\end{array}$ & bottom \\
\hline 8 & EURO000241 & EURO000241 & Building & 4850 & Row & 2 & Position & 4 & $\begin{array}{l}\text { Vertical } \\
\text { Location }\end{array}$ & bottom \\
\hline 9 & UREU455008 & UREU455008 & Building & 4850 & Row & 2 & Position & 11 & $\begin{array}{l}\text { Vertical } \\
\text { Location }\end{array}$ & bottom \\
\hline 10 & LUZU000623 & LUZU000623 & Building & 4850 & Row & 2 & Position & 12 & $\begin{array}{l}\text { Vertical } \\
\text { Location }\end{array}$ & bottom \\
\hline 11 & UREU101306 & UREU101306 & Building & 3600 & Row & 1 & Position & 1 & $\begin{array}{l}\text { Vertical } \\
\text { Location }\end{array}$ & middle \\
\hline 12 & BNFU000097 & BNFU000097 & Building & 3600 & Row & 1 & Position & 2 & $\begin{array}{l}\text { Vertical } \\
\text { Location }\end{array}$ & middle \\
\hline 13 & 275 & EURO000275 & Building & 3600 & Row & 1 & Position & 3 & $\begin{array}{l}\text { Vertical } \\
\text { Location }\end{array}$ & middle \\
\hline 14 & UREU455033 & UREU455033 & Building & 3600 & Row & 1 & Position & 4 & $\begin{array}{l}\text { Vertical } \\
\text { Location }\end{array}$ & middle \\
\hline 15 & LUXU00022 & LUXU00022 & Building & 3600 & Row & 1 & Position & 11 & $\begin{array}{l}\text { Vertical } \\
\text { Location }\end{array}$ & middle \\
\hline 16 & LUXU000667 & LUXU000667 & Building & 3600 & Row & 3 & Position & 1 & $\begin{array}{l}\text { Vertical } \\
\text { Location }\end{array}$ & middle \\
\hline 17 & LUXU002440 & LUXU002440 & Building & 3600 & Row & 3 & Position & 2 & $\begin{array}{l}\text { Vertical } \\
\text { Location }\end{array}$ & middle \\
\hline 18 & BNFU002583 & BNFU002583 & Building & 3600 & Row & 3 & Position & 3 & $\begin{array}{l}\text { Vertical } \\
\text { Location }\end{array}$ & middle \\
\hline 19 & UREU45503 & UREU45503 & Building & 3600 & Row & $X Y$ & Position & 4 & $\begin{array}{l}\text { Vertical } \\
\text { Location }\end{array}$ & middle \\
\hline 20 & UREU122154 & UREU122154 & Building & 3600 & Row & $\mathrm{ZA}$ & Position & 11 & $\begin{array}{l}\text { Vertical } \\
\text { Location }\end{array}$ & middle \\
\hline 21 & UREU033645 & UREU033645 & Raft & XA & Column & 1 & Position & 1 & & \\
\hline 22 & LUXU000130 & LUXU000130 & Raft & XA & Column & 1 & Position & 2 & & \\
\hline 23 & UREU033654 & UREU0336454 & Raft & A & Column & 1 & Position & 1 & & \\
\hline 24 & LUXU000103 & LUXU000103 & Raft & A & Column & 1 & Position & 2 & & \\
\hline 25 & BNFU127082 & BNFU127082 & Building & 5780 & Feed & 1 & & & & \\
\hline 26 & UREU103126 & UREU103126 & Building & 5780 & Feed & 2 & & & & \\
\hline 27 & BNFU003025 & BNFU003025 & Building & 5780 & Product & 1 & & & & \\
\hline 28 & LUZU000324 & LUZU000324 & Building & 5780 & Product & 2 & & & & \\
\hline 29 & UREU101172 & UREU101172 & Building & 5780 & Tails & 1 & & & & \\
\hline 30 & UREU101854 & UREU101854 & Building & 5780 & Tails & 2 & & & & \\
\hline 31 & UREU103609 & UREU103609 & Building & 5780 & $\begin{array}{c}\text { Feed } \\
\text { Purification }\end{array}$ & 1 & & & & \\
\hline 32 & SETU000239 & SETU000239 & Building & 5780 & $\begin{array}{c}\text { Feed } \\
\text { Purification }\end{array}$ & 2 & & & & \\
\hline
\end{tabular}



APPENDIX B. USER FLOW 



\section{APPENDIX B. USER FLOW}

\section{B.1 PREPARING MOBILE DEVICE}

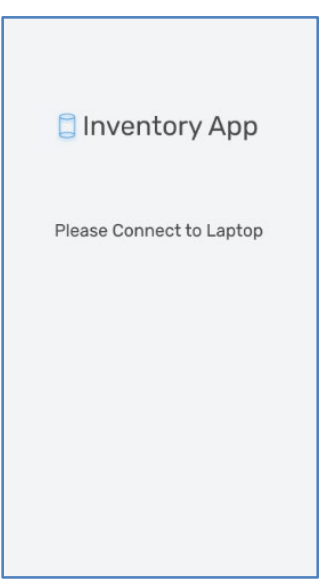

Figure B-1. Step 1 Preparing Mobile Device. In-Field Observations App before the assigned inventory list is downloaded from the office computer.

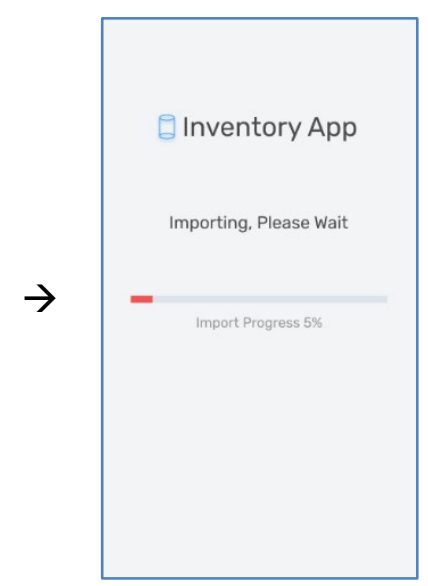

Figure B-2. Step 1aPreparing Mobile Device. In-Field Observations App during the download process.

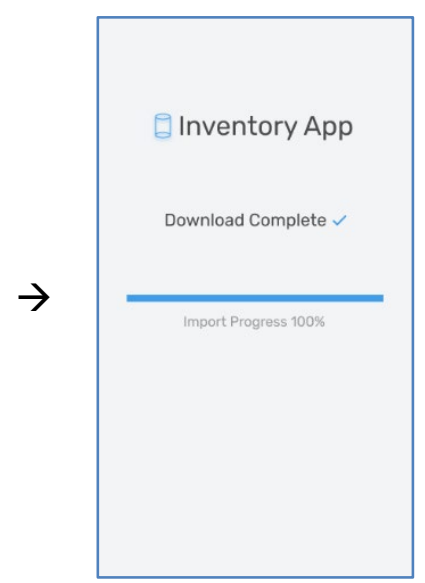

Figure B-3. Step 1b Preparing Mobile

Device. Successful download of the assigned inventory list to the mobile device.

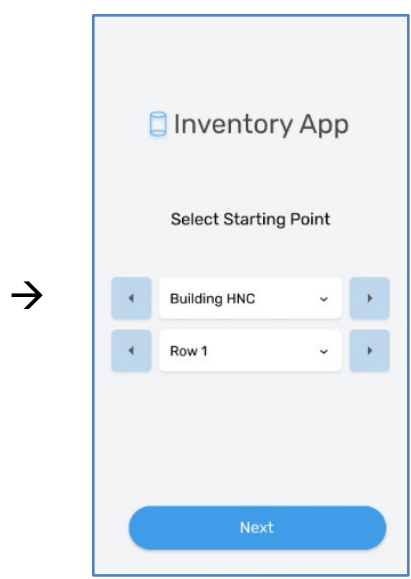

Figure B-4. Step 1cPreparing Mobile

Device. Select the starting location in the field for field observation activities.

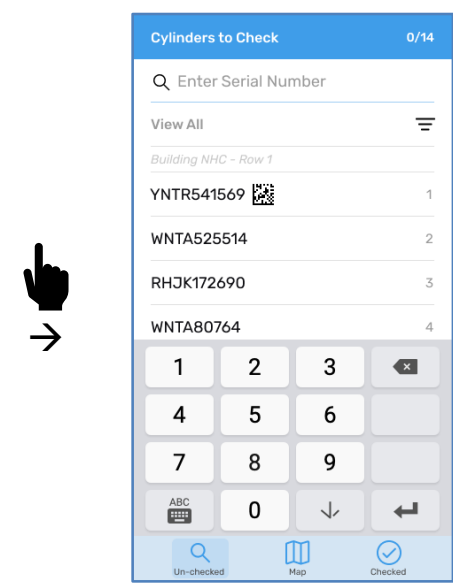

Figure B-5. Step 2 Field Observations.

"To Observe" inventory list ordered by location (next item expected). Items with two-

dimensional barcode show a Data Matrix icon to the right of the identification number. 


\section{B.2 FIELD OBSERVATIONS}

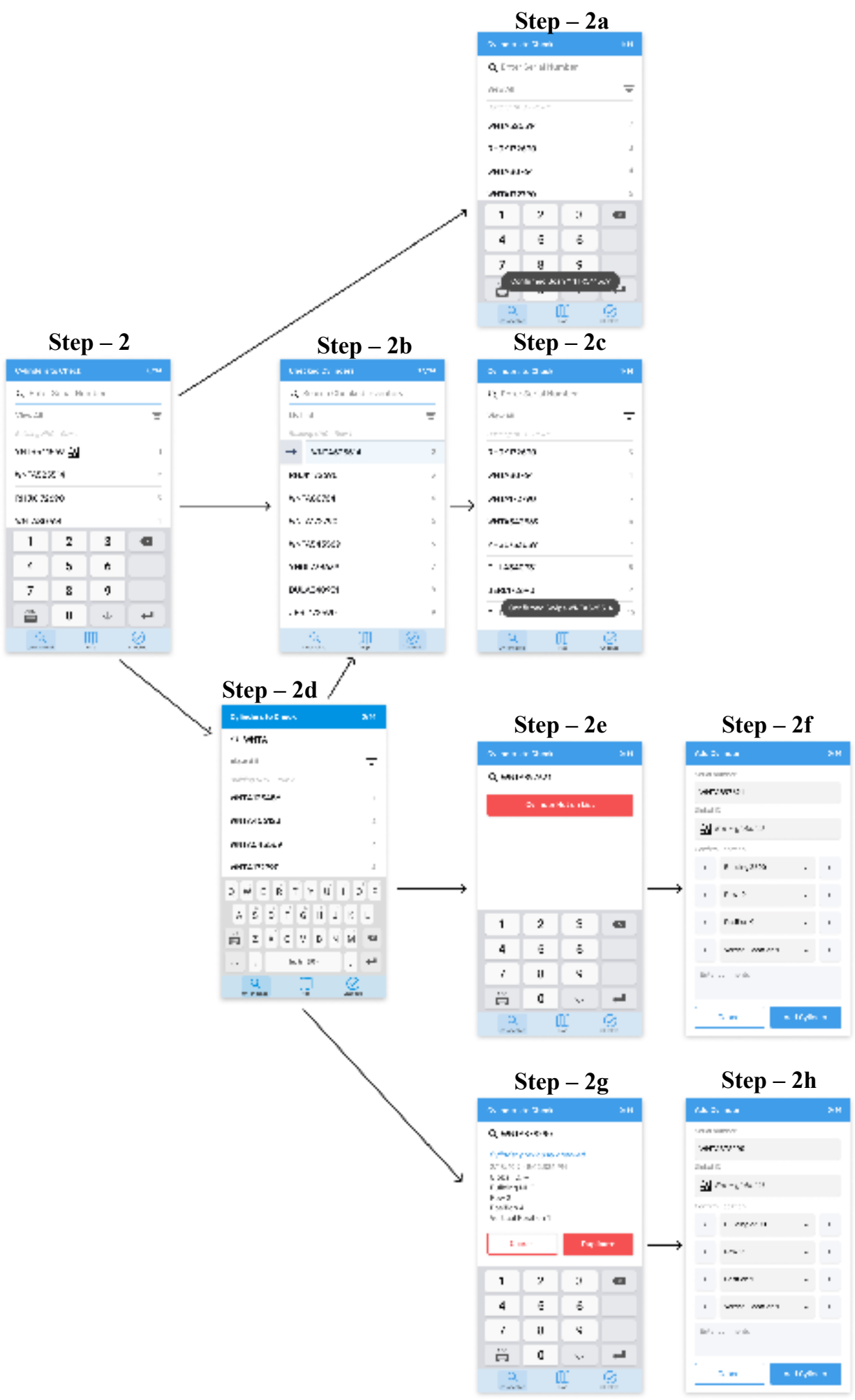

Figure B-6. Step 2 - Field Observations. Overview of user experience workflow. 


\begin{tabular}{|c|c|c|c|}
\hline \multicolumn{3}{|c|}{ Cylinders to Check } & $0 / 14$ \\
\hline \multicolumn{4}{|c|}{ Q Enter Serial Number } \\
\hline \multicolumn{3}{|c|}{ View All } & $\bar{\equiv}$ \\
\hline \multicolumn{4}{|c|}{ Building NHC - Row 1} \\
\hline \multicolumn{3}{|c|}{ YNTR541569 戟 } & 1 \\
\hline \multicolumn{3}{|c|}{ WNTA525514 } & 2 \\
\hline \multicolumn{3}{|c|}{ RHJK172690 } & 3 \\
\hline \multicolumn{3}{|c|}{ WNTA80764 } & 4 \\
\hline 1 & 2 & 3 & $x$ \\
\hline 4 & 5 & 6 & \\
\hline 7 & 8 & 9 & \\
\hline $\begin{array}{l}\mathrm{ABC} \\
\stackrel{\mathrm{W}}{\mathrm{W}}\end{array}$ & 0 & $\sqrt{ }$ & 山 \\
\hline Un-ch & & & \\
\hline
\end{tabular}

Figure B-7. Step 2 - Field

Observations. "To Observe" inventory list ordered by location (next item expected).
Cylinders to Check

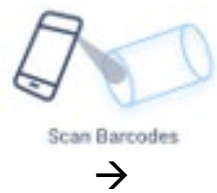

Q Enter Serial Number

View All $\equiv$

Building NHC - Row 1

WNTA525514

2

RHJK172690

WNTA80764

WNTA172790

\begin{tabular}{|c|c|c|c|}
\hline 1 & 2 & 3 & $\times$ \\
\hline 4 & 5 & 6 \\
\hline 7 & 8 & 9 \\
\hline
\end{tabular}

Figure B-8. Step 2a - Field

Observations. Observe item by scanning identification barcode. Pop-up notification confirms successful scan of item YNTR541569. Observed item identification number is removed from display and the "To Observe" inventory list advances to the next expected item. 


\begin{tabular}{|c|c|c|c|}
\hline \multicolumn{3}{|c|}{ Cylinders to Check } & $0 / 14$ \\
\hline \multicolumn{4}{|c|}{ Q Enter Serial Number } \\
\hline \multicolumn{3}{|c|}{ View All } & $\overline{\bar{N}}$ \\
\hline \multicolumn{4}{|c|}{ Building NHC - Row 1} \\
\hline \multicolumn{3}{|c|}{ YNTR541569 继 } & 1 \\
\hline \multicolumn{3}{|c|}{ WNTA525514 } & 2 \\
\hline \multicolumn{3}{|c|}{ RHJK172690 } & 3 \\
\hline \multicolumn{3}{|c|}{ WNTA80764 } & 4 \\
\hline 1 & 2 & 3 & $x$ \\
\hline 4 & 5 & 6 & \\
\hline 7 & 8 & 9 & \\
\hline 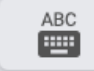 & 0 & $\checkmark$ & 山 \\
\hline Un-ch & & & ked \\
\hline
\end{tabular}

Figure B-9. Step 2 - Field

Observations. "To Observe" inventory list ordered by location (next item expected).

\begin{tabular}{|lr|}
\hline Checked Cylinders & $13 / 14$ \\
\hline Q Search Checked Inventory & \\
\hline My List & $\overline{1}$ \\
\hline Building NHC - Row 1 & 2 \\
\hline WNTA525514 & 3 \\
\hline RHJK172690 & 4 \\
\hline WNTA80764 & 5 \\
\hline WNTA172790 & 6 \\
\hline WNTA543569 & 8 \\
\hline YHGL733639 & 9 \\
\hline DULA340931 & \\
\hline JERL172690 & Map \\
\hline Unchecked & \\
\hline
\end{tabular}

Figure B-10 Figure 19. Step 2b - Field Observations. If observed item

identification number is displayed on the mobile device screen, swipe right to observe item (e.g., WNTA525514).

\begin{tabular}{|lr|}
\hline Cylinders to Check & $1 / 14$ \\
\hline Q Enter Serial Number & $\overline{1}$ \\
\hline View All & \\
\hline Building NHC - Row 1 & 3 \\
\hline RHJK172690 & 4 \\
\hline WNTA80764 & 5 \\
\hline WNTA172790 & 6 \\
\hline WNTA543569 & 7 \\
\hline YHGL733639 & 8 \\
\hline DULA340931 & 9 \\
\hline JERL172690 & 10 \\
\hline DUL Confirmed Swipe WNTA525514 & 10 \\
\hline \begin{tabular}{l} 
Un-checked \\
\hline
\end{tabular} & \\
\hline Map & \\
\hline
\end{tabular}

Figure B-11. Step 2c - Field Observations. Pop-up notification confirms successful swipe of item WNTA525514. Observed item identification number is removed from display and the "To Observe" inventory list advances to the next expected item. 


\begin{tabular}{|c|c|c|c|}
\hline \multicolumn{3}{|c|}{ Cylinders to Check } & $0 / 14$ \\
\hline \multicolumn{4}{|c|}{ Q Enter Serial Number } \\
\hline \multicolumn{3}{|c|}{ View All } & $\equiv$ \\
\hline \multicolumn{4}{|c|}{ Building NHC - Row 1} \\
\hline \multicolumn{3}{|c|}{ YNTR541569 通 } & 1 \\
\hline \multicolumn{3}{|c|}{ WNTA525514 } & 2 \\
\hline \multicolumn{3}{|c|}{ RHJK172690 } & 3 \\
\hline \multicolumn{3}{|c|}{ WNTA80764 } & 4 \\
\hline 1 & 2 & 3 & $\mathbf{x}$ \\
\hline 4 & 5 & 6 & \\
\hline 7 & 8 & 9 & \\
\hline$\stackrel{\text { ABC }}{\mathrm{BB}}$ & 0 & $\checkmark$ & 山 \\
\hline Un:et & & & (vected \\
\hline
\end{tabular}

Figure B-12. Step 2 - Field Observations. "To Observe" inventory list ordered by location (next item expected).

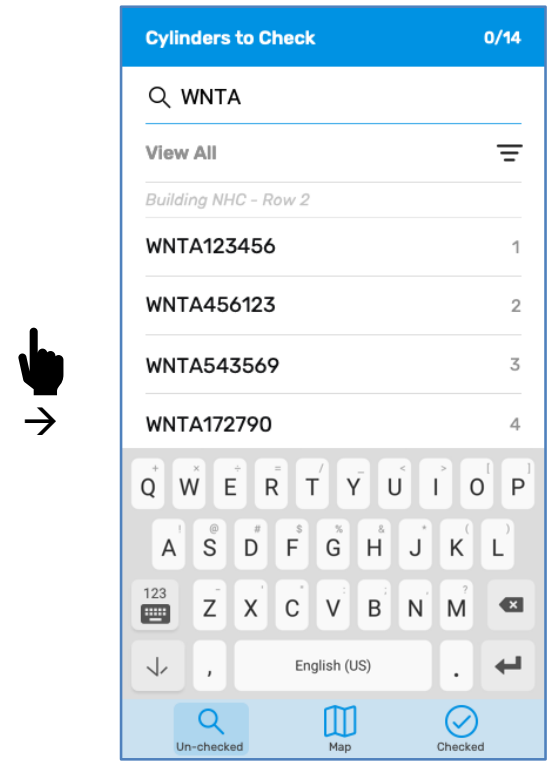

Figure B-13. Step 2d - Field Observations. Search "To

Observe" inventory list by typing identification number into the search field (e.g., WNTA...).

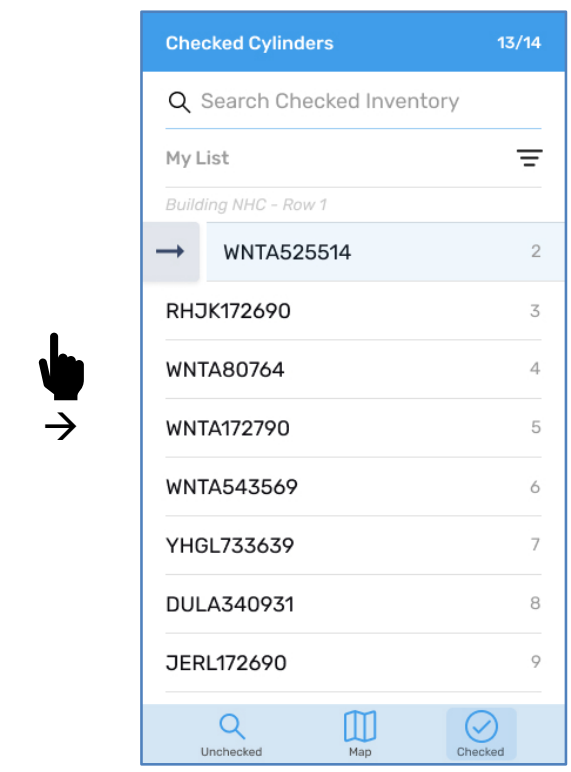

Figure B-14. Step 2b - Field Observations. Once the

observed item identification number is displayed on the mobile device screen, swipe right to observe item (e.g., WNTA525514).

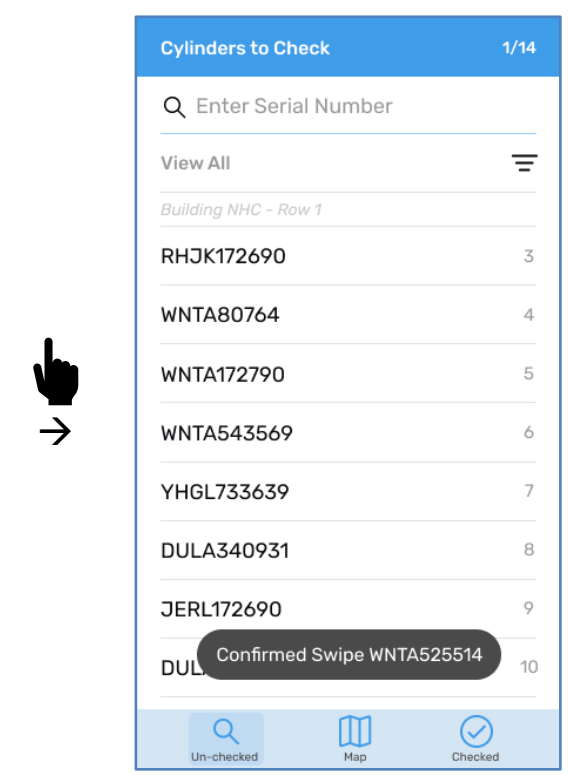

Figure B-15. Step 2c - Field Observations. Pop-up notification confirms successful swipe of item WNTA525514. Observed item identification number is removed from display and the "To Observe" inventory list advances to the next expected item. 


\begin{tabular}{|c|c|c|c|}
\hline \multicolumn{3}{|c|}{ Cylinders to Check } & 0/14 \\
\hline \multicolumn{4}{|c|}{ Q Enter Serial Number } \\
\hline \multicolumn{3}{|c|}{ View All } & $\equiv$ \\
\hline \multicolumn{4}{|c|}{ Building NHC - Row 1} \\
\hline \multicolumn{3}{|c|}{ YNTR541569 触 } & 1 \\
\hline \multicolumn{3}{|c|}{ WNTA525514 } & 2 \\
\hline \multicolumn{3}{|c|}{ RHJK172690 } & 3 \\
\hline \multicolumn{3}{|c|}{ WNTA80764 } & 4 \\
\hline 1 & 2 & 3 & $x$ \\
\hline 4 & 5 & 6 & \\
\hline 7 & 8 & 9 & \\
\hline$\stackrel{\text { ABC }}{\text { 腮 }}$ & 0 & $\sqrt{ }$ & $\leftrightarrow$ \\
\hline & & & 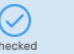 \\
\hline
\end{tabular}

Figure B-16. Step 2 - Field Observations. "To Observe" inventory list ordered by location (next item expected).

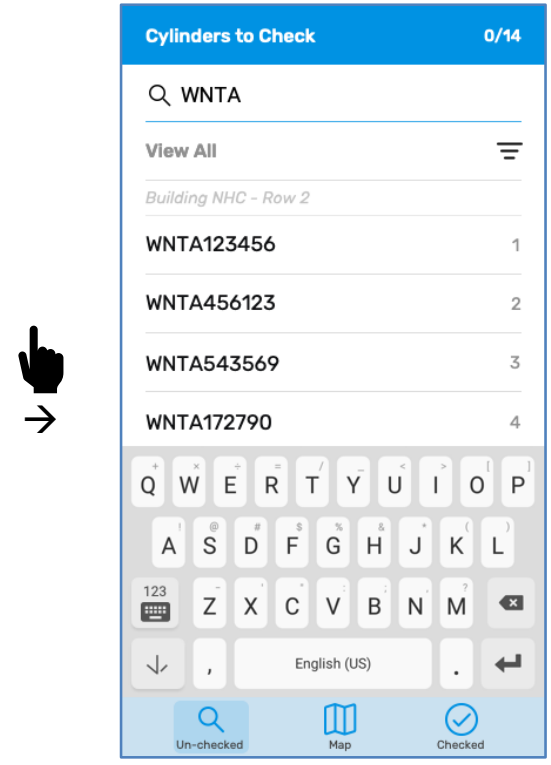

Figure B-17. Step 2d - Field Observations. Search "To

Observe" inventory list by typing identification number into the search field (e.g., WNTA...).
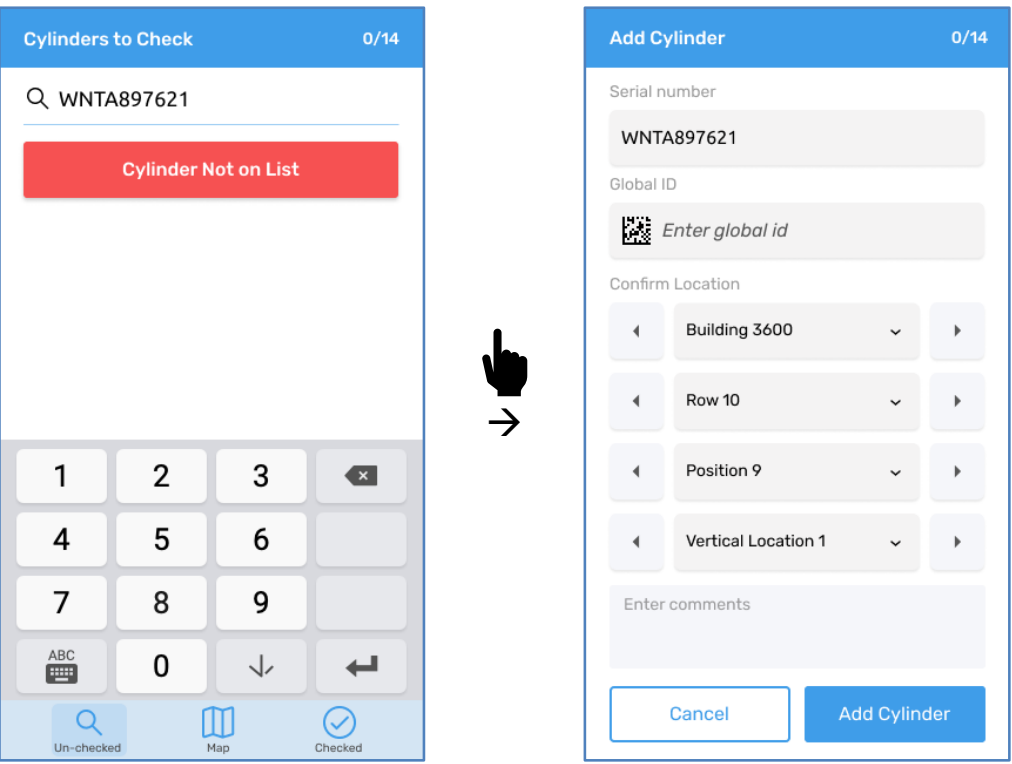

Figure B-18. Step 2e - Field

Observations. New screen is

displayed if the searched item (e.g., WNTA897621) is not on the inventory list. Inventory team must select the red button to advance to the next screen.

\section{Figure B-19. Step 2f - Field} Observations. Add item identification number

WNTA897621 and location to the observed inventory list. Identification number and location are automatically populated based on the location of the most recently observed item, but the inventory team can update. 


\begin{tabular}{|c|c|c|c|}
\hline \multicolumn{3}{|c|}{ Cylinders to Check } & 0/14 \\
\hline \multicolumn{4}{|c|}{ Q Enter Serial Number } \\
\hline \multicolumn{3}{|c|}{ View All } & $\equiv$ \\
\hline \multicolumn{4}{|c|}{ Bullding NHC - Row 1} \\
\hline \multicolumn{3}{|c|}{ YNTR541569 触 } & 1 \\
\hline \multicolumn{3}{|c|}{ WNTA525514 } & 2 \\
\hline \multicolumn{3}{|c|}{ RHJK172690 } & 3 \\
\hline \multicolumn{3}{|c|}{ WNTA80764 } & 4 \\
\hline 1 & 2 & 3 & $x$ \\
\hline 4 & 5 & 6 & \\
\hline 7 & 8 & 9 & \\
\hline 甚要 & 0 & $\checkmark$ & 山 \\
\hline Un-che & & & $\bigodot_{\text {nected }}$ \\
\hline
\end{tabular}

Figure B-20. Step 2 - Field Observations. "To Observe" inventory list ordered by location (next item expected).

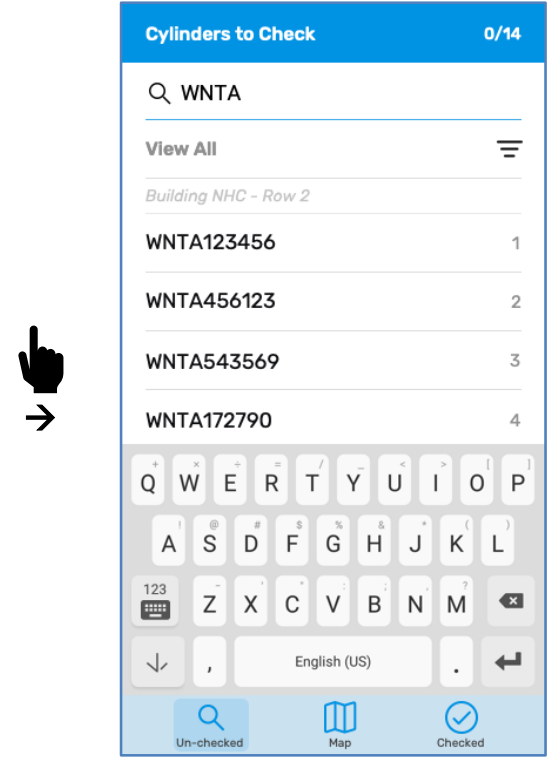

Figure B-21. Step 2d - Field Observations. Search "To

Observe" inventory list by

typing identification number into the search field (e.g., WNTA...).
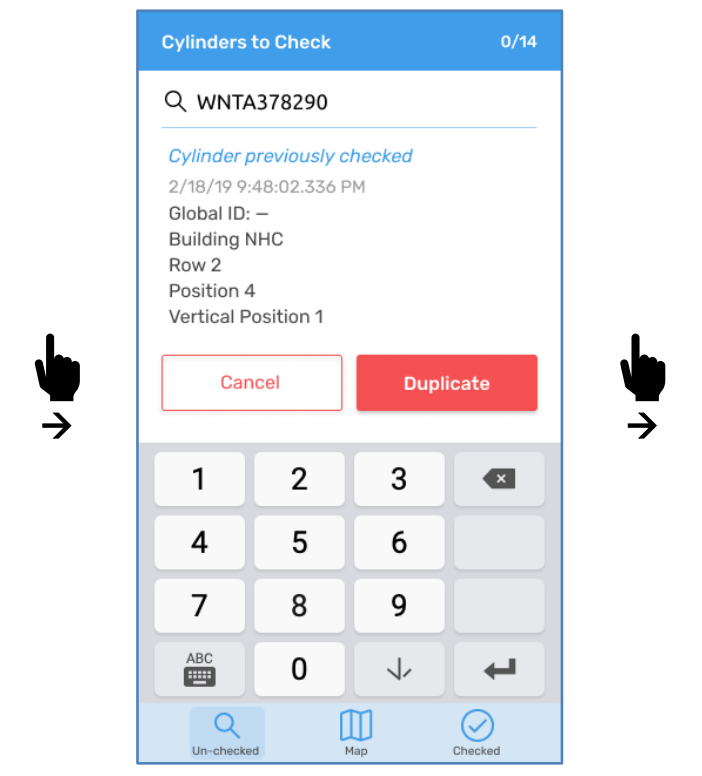

Figure B-22. Step 2g - Field

Observations. New screen is displayed if the searched item identification number (e.g., WNTA378290) has been previously observed. The observation time stamp is displayed. Inventory team may choose to duplicate the item identification number or cancel entry.

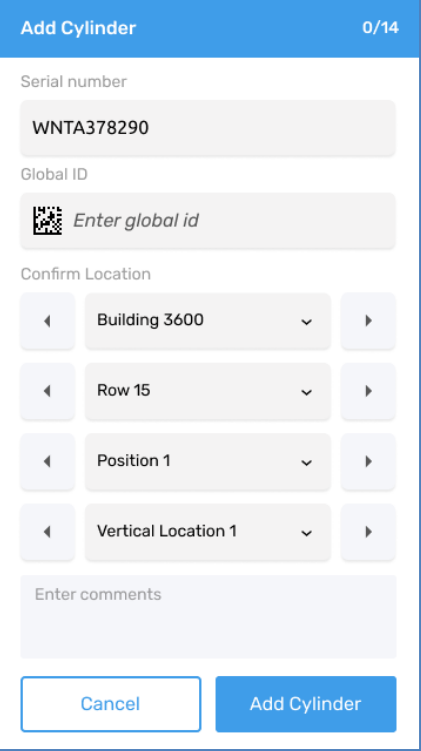

Figure B-23. Step 2h - Field Observations. Confirm location of duplicate item WNTA378290. Identification number and location are automatically populated with default location based on the location of the most recently observed item, but the inventory team can update. 


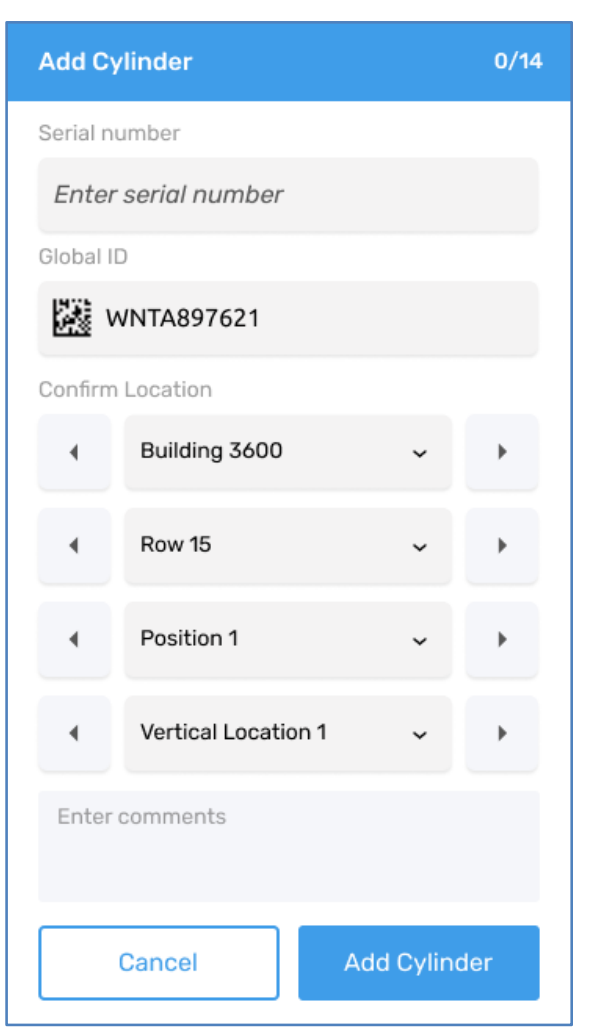

Figure B-24. Step 3 - Enter Location of an Item Added to List. A barcode is scanned by the mobile device. The mobile device screen displays the default location based on the location of the most recently observed item. The inventory team can change the location by selecting from a series of drop-down menus.

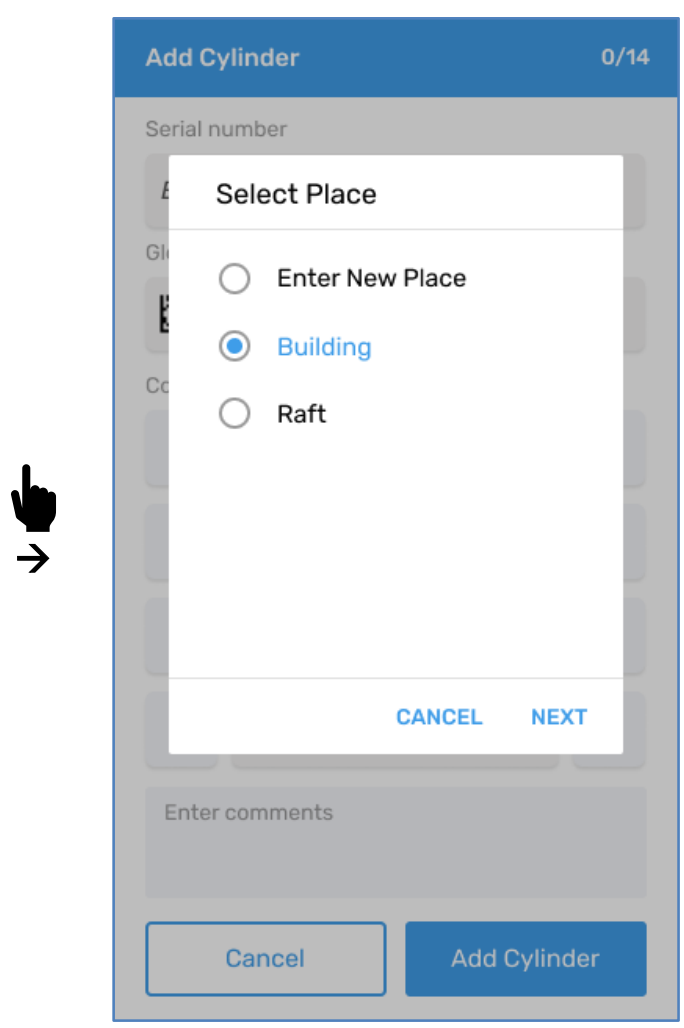

Figure B-25. Step 3a - Enter Location of an Item Added to List. The

inventory team proceeds through the available selections for the location hierarchy. First, the mobile device screen displays the place (level 0 prefix) options. The inventory team can select from the listed options or cancel.

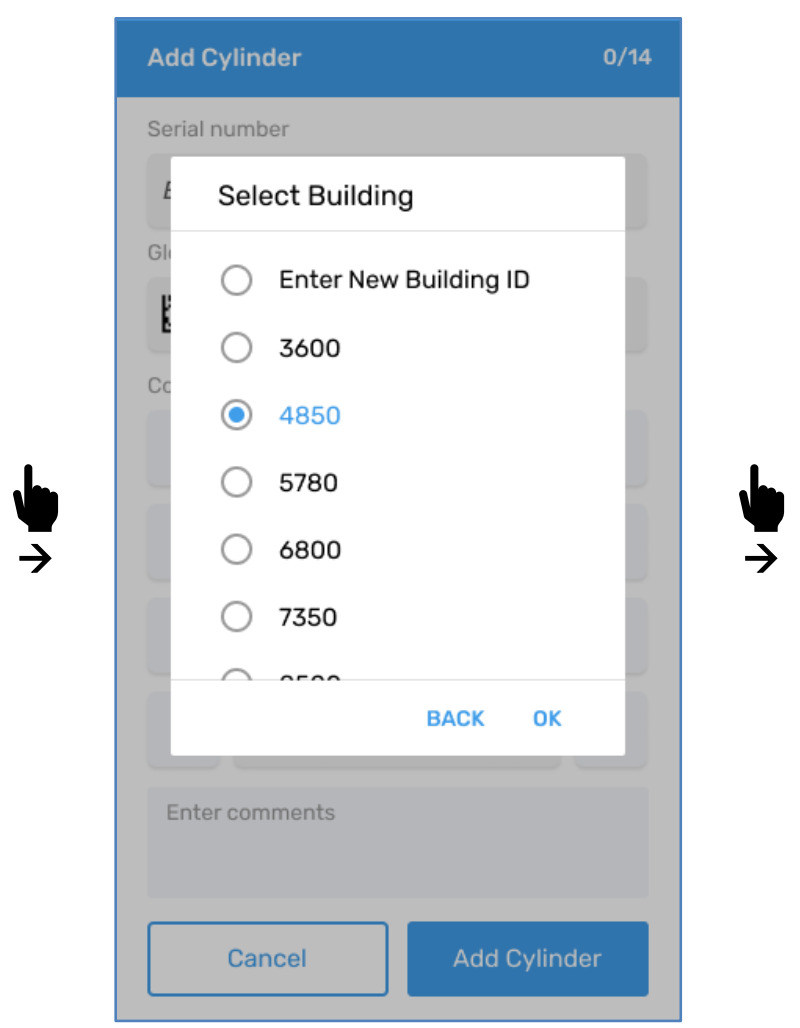

Figure B-26. Step 3b - Enter Location of an Item Added to List. After selecting "Building," the mobile device screen displays the place number (level 0 ) options. The inventory team can select from the listed options or cancel. 


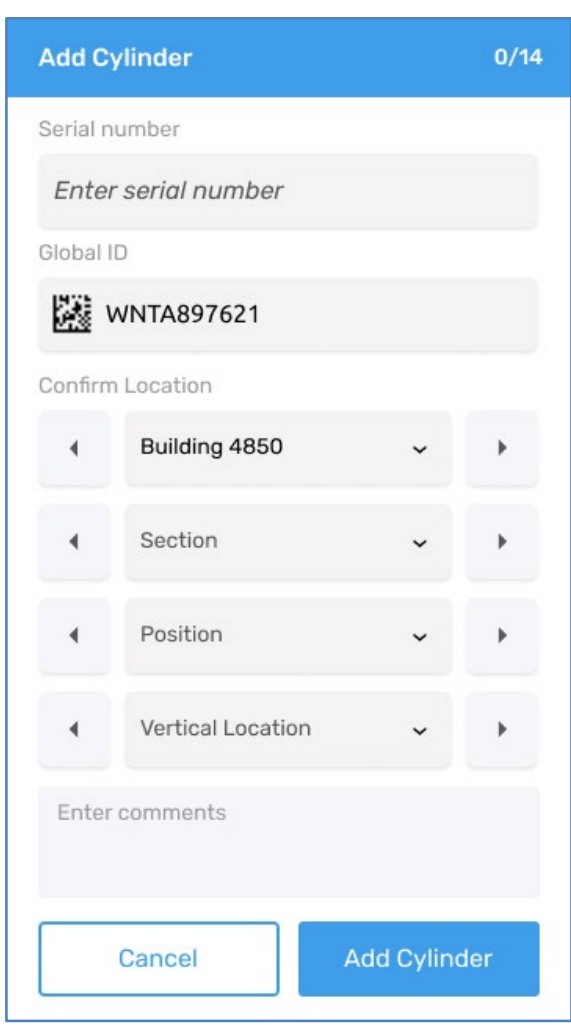

Figure B-27. Step 3c - Enter Location of an Item Added to List. After

selecting the place "Building 4850," the inventory team must navigate to the section (level 1 prefix) options.

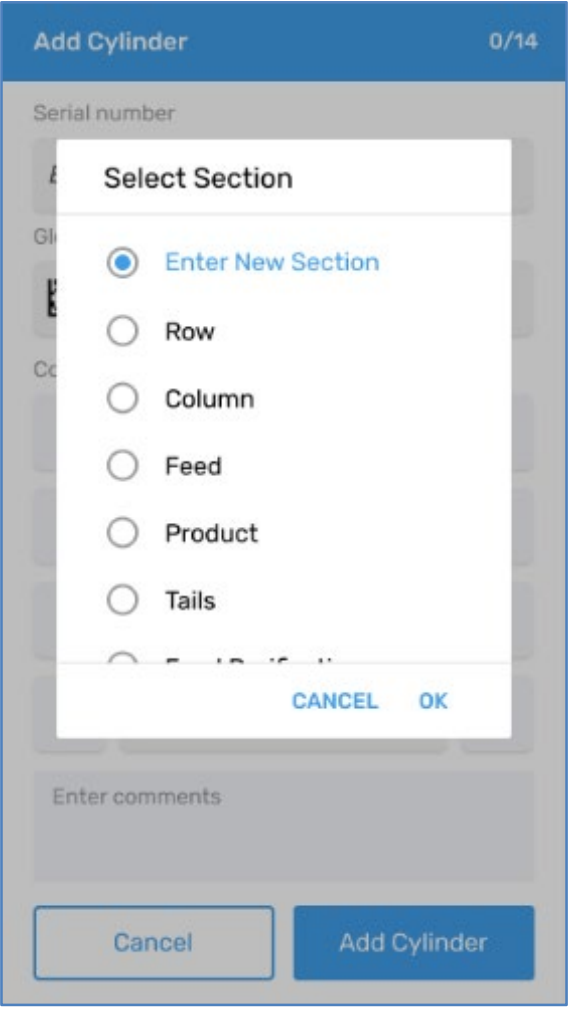

Figure B-28. Step 3d-Enter Location of an Item Added to List. The mobile device screen displays the section (level 1 prefix) options. The inventory team can select from the listed options or cancel.

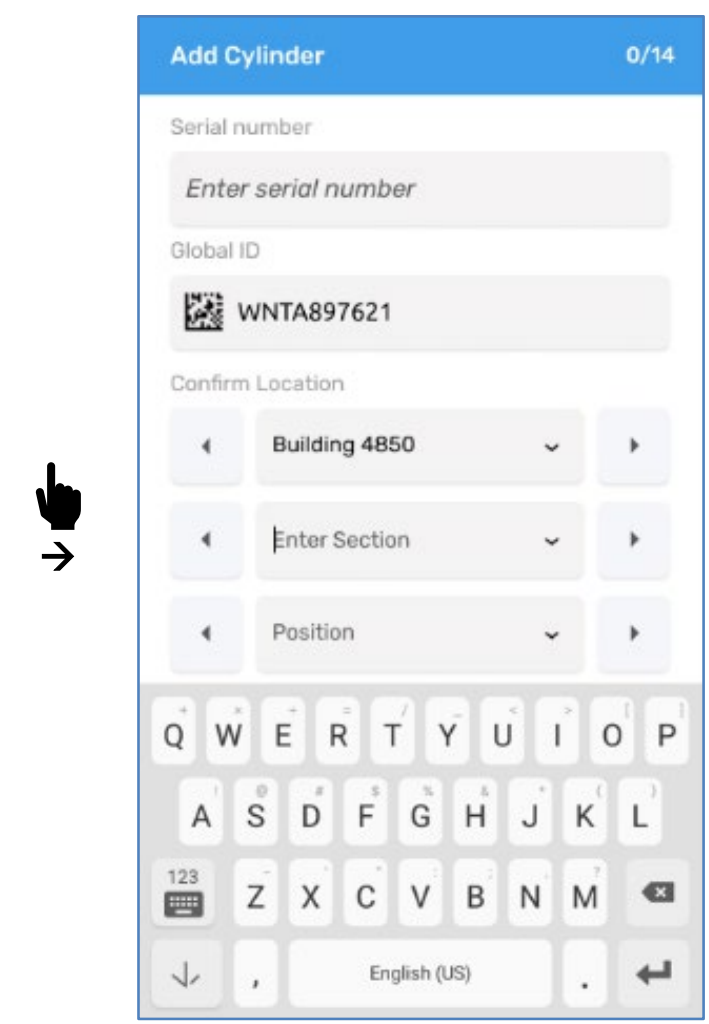

Figure B-29. Step 3e-Enter Location of an Item Added to List. After

selecting "Enter New Section," the mobile device screen displays the alphanumeric keyboard and the inventory team types in the section (level 1). A similar workflow is followed for selecting the "Position" and "Vertical Location" as displayed in Figure 45. 


\begin{tabular}{|c|c|}
\hline Checked Cylinders & $13 / 14$ \\
\hline \multicolumn{2}{|c|}{ Q Search Checked Inventory } \\
\hline My List & $\bar{\equiv}$ \\
\hline \multicolumn{2}{|l|}{ Building NHC - Row 1} \\
\hline WNTA25514 & 1 \\
\hline KYTL123456 & 2 \\
\hline YNTR541569 & 3 \\
\hline RHJK172690 & 4 \\
\hline WNTA80764 & 5 \\
\hline YHGL733639 & 6 \\
\hline DULA340931 & 7 \\
\hline JERL172690 & 8 \\
\hline$\underset{\text { Unchecked }}{Q}$ & \\
\hline
\end{tabular}

Figure B-30. Step 4 - Observed inventory list. Observed inventory list ordered by most recently observed.

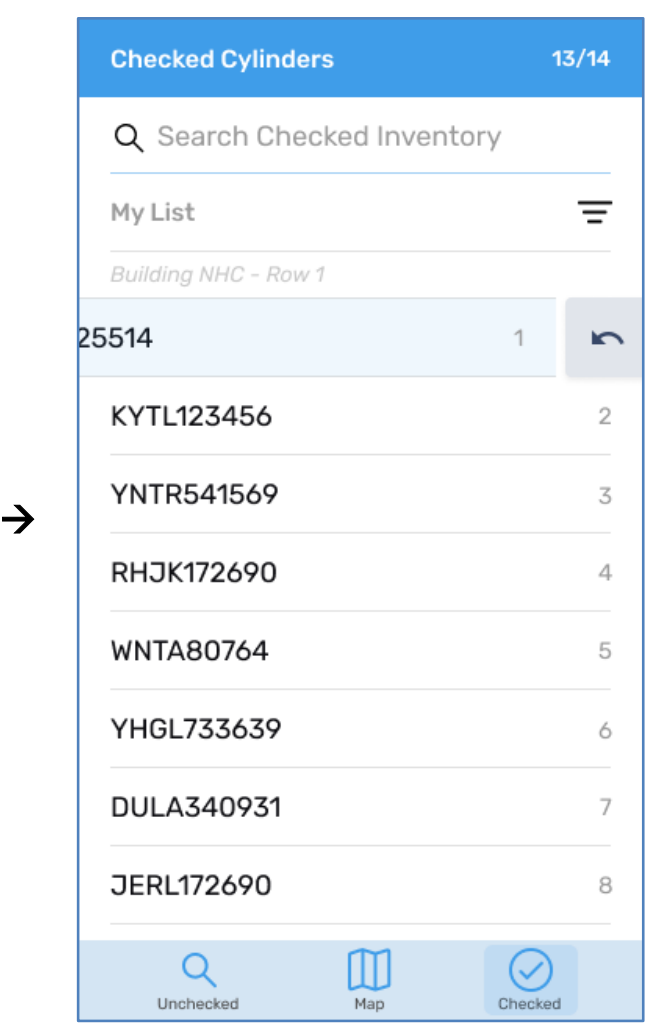

Figure B-31. Step 4a-Observed inventory list. Swipe left to revise an observation for an item identification number (e.g., WNTA25514).

\begin{tabular}{|lr|}
\hline Checked Cylinders & $13 / 14$ \\
\hline Q Search Checked Inventory & \\
\hline My List & $\overline{1}$ \\
\hline Building NHC - Row 1 & 2 \\
\hline KYTL123456 & 3 \\
\hline YNTR541569 & 4 \\
\hline RHJK172690 & 5 \\
\hline WNTA80764 & 6 \\
\hline YHGL733639 & 8 \\
\hline DULA340931 & 9 \\
\hline JERL172690 & \\
\hline JE Moved to Unchecked WNTA525514 & 9 \\
\hline Unchecked & Map \\
\hline
\end{tabular}

Figure B-32. Step 4b - Observed inventory list. A pop-up notifies the inventory team that item WNTA525514 has moved from the observed list to the "To Observe" inventory list. 


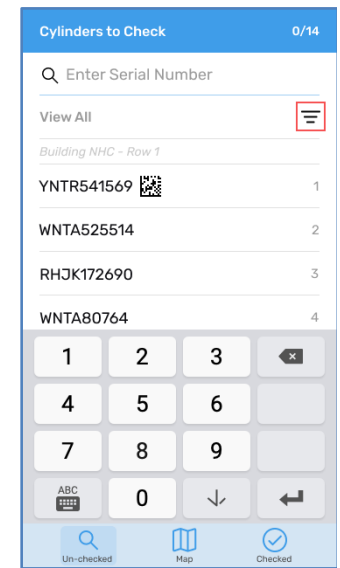

Figure B-33. Step 5 - Filtering. If the inventory team wants to filter their view of the item

identification numbers, they first select the filter/sort icon boxed in red in the upper right corner of the screen.
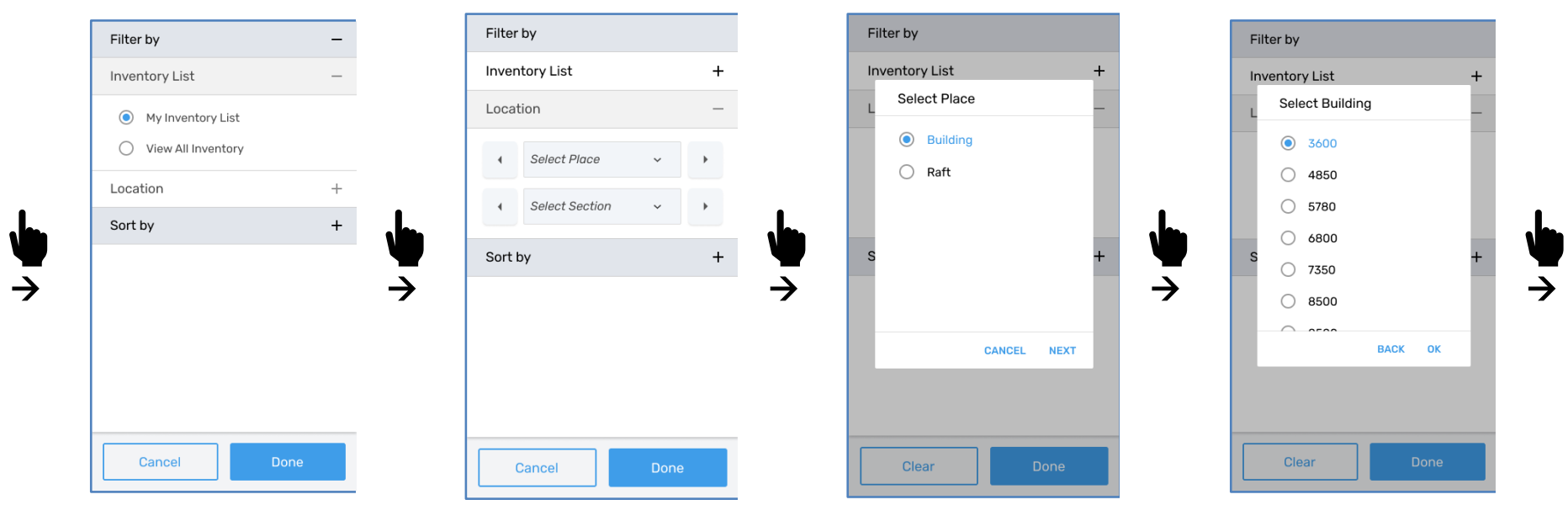

Figure B-34. Step 5a-Filtering. The default filtering view displays the inventory list by "My Inventory List." This is the assigned inventory list for a given inventory team.
Figure B-35. Step 5b - Filtering. The inventory team also has the option to filter the assigned inventory list by location (place and section).
Figure B-36. Step 5c - Filtering. If

filtering by location, the inventory team first selects the place, or level 0 prefix (e.g., Building).
Figure B-37. Step 5d - Filtering. The inventory team then selects the place number or level 0 value (e.g., 3600). 


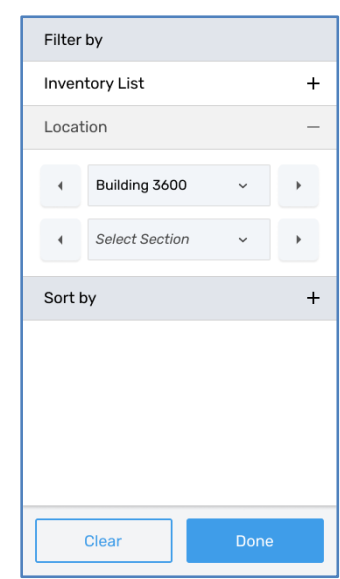

Figure B-38. Step 5e

- Filtering. The place

(e.g., Building 3600) is successfully

selected by the inventory team.

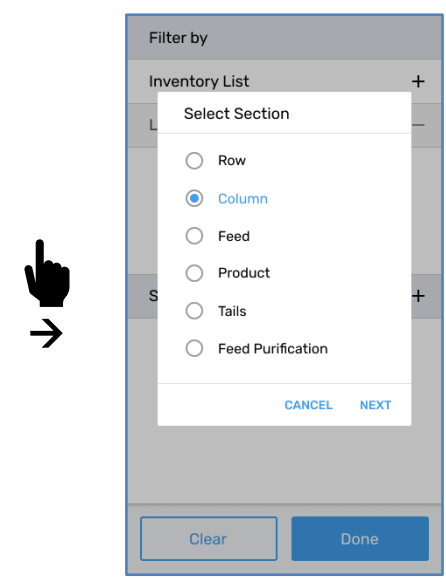

Figure B-39. Step 5f

- Filtering. Next, the

inventory team selects the section or level 1 prefix (e.g., Column).

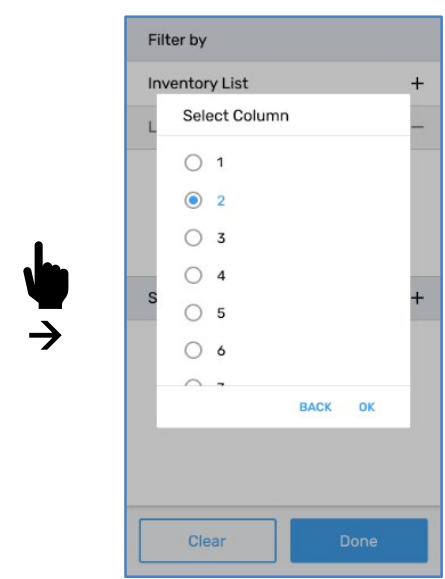

Figure B-40. Step 5g

- Filtering. The

inventory team then

selects the section

number or level 1

value (e.g., 2).

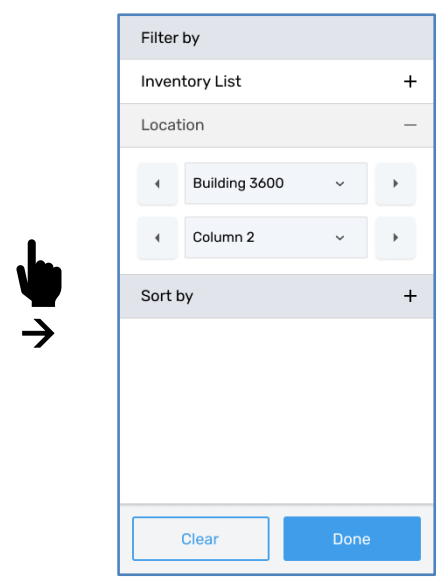

Figure B-41. Step 5h

- Filtering. The place

(e.g., Building 3600) and section (e.g.,

Column 2) are successfully selected by the inventory team.

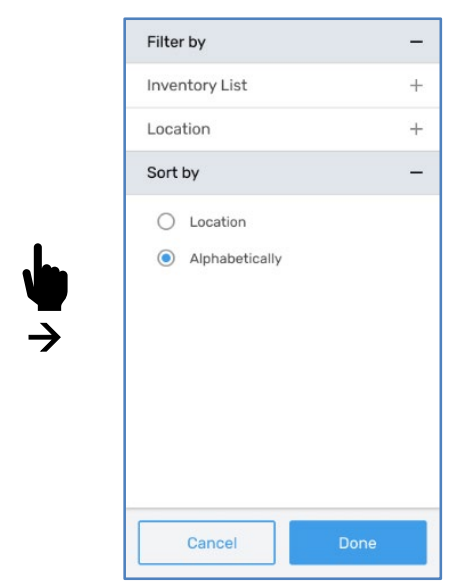

Figure B-42. Step 5i - Filtering.

Additionally, the inventory team may

choose to sort the assigned inventory list alphabetically (default view of the assigned inventory list is sorted by location). 


\begin{tabular}{|c|c|c|c|}
\hline \multicolumn{3}{|c|}{ Cylinders to Check } & $0 / 14$ \\
\hline \multicolumn{4}{|c|}{ Q Enter Serial Number } \\
\hline \multicolumn{3}{|c|}{ View All } & $\bar{\equiv}$ \\
\hline \multicolumn{4}{|c|}{ Building NHC - Row 1} \\
\hline \multicolumn{3}{|c|}{ YNTR541569 敬 } & 1 \\
\hline \multicolumn{3}{|c|}{ WNTA525514 } & 2 \\
\hline \multicolumn{3}{|c|}{ RHJK172690 } & 3 \\
\hline \multicolumn{3}{|c|}{ WNTA80764 } & 4 \\
\hline 1 & 2 & 3 & $x$ \\
\hline 4 & 5 & 6 & \\
\hline 7 & 8 & 9 & \\
\hline$\stackrel{A B C}{\#}$ & 0 & $\sqrt{ }$ & 山 \\
\hline & & & cked \\
\hline
\end{tabular}

Figure B-43. Step 6 - Item Information. If an inventory team member long taps on an item identification number, the item information page is displayed.

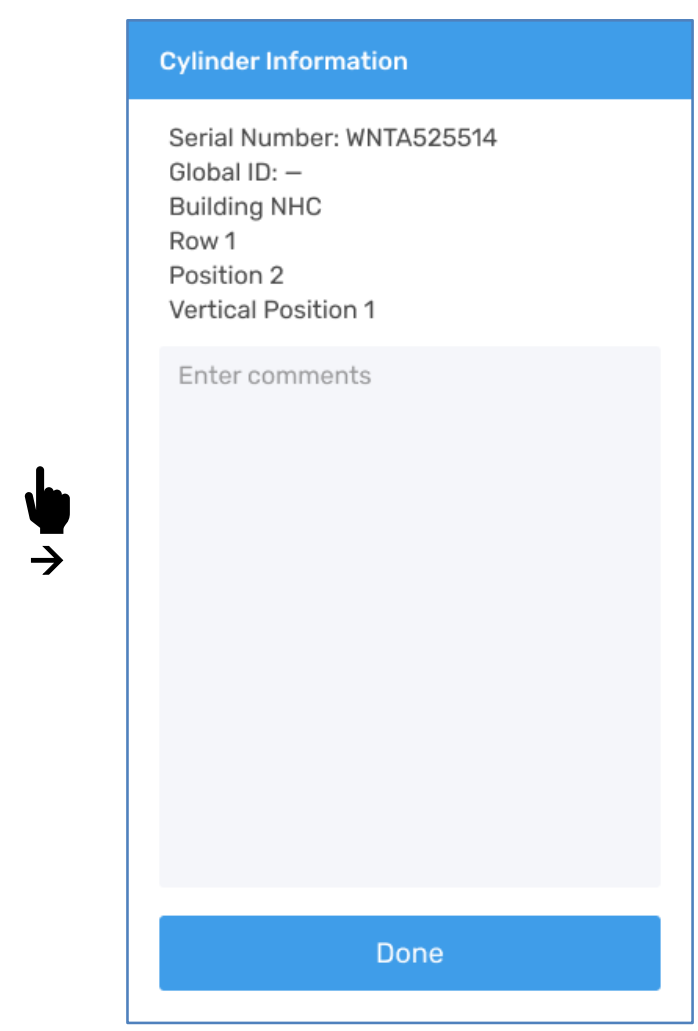

Figure B-44. Step 6a - Item Information. Item information page includes identification numbers (e.g., serial number, global identification number), location, and inventory team comments. 
